\title{
GEOQUÍMICA DE ÁGUAS SUBTERRÂNEAS IMPACTADAS POR ATERROS DE RESÍDUOS SÓLIDOS
}

\author{
GEOCHEMISTRY OF GROUNDWATERS IMPACTED \\ BY LANDFILLS OF SOLID WASTES
}

Carlos Frederico de Castro Alves ${ }^{1}$, Reginaldo Antonio Bertolo ${ }^{2}$

Artigo recebido em: 16/02/2012 e aceito para publicação em: 14/06/2012

\begin{abstract}
Aquifer contamination is one of the main environmental impacts caused by the inadequate disposal of solid wastes. This contamination occurs when the solid waste leachate reaches this environment. Groundwater affected by leachates presents several biogeochemical processes in time and space, which vary according to the characteristics of leachate and local hydrogeology. These processes induce the formation of different redox zones in the subsurface environment which, in turn, determine the behavior of several substances from the leachate itself and others formed by the interaction between groundwater, leachate and the geological medium. Some of these substances may produce risks for both human and ecological receptors. Therefore, the understanding of the behavior of these substances in the subsurface is the key to establish environmental measures for rehabilitation of the waste disposal facilities. In this context, this article presents a review of the literature about: (a) the mechanisms of leachate formation and its composition and (b) biogeochemical environment and composition of leachate-affected groundwater. This subject is of particular importance considering the National Policy on Solid Waste that predicts that all unlined landfills should be investigated and eradicated in Brazil until 2014.
\end{abstract}

Keywords: Solid waste, landfill, biogeochemistry, aquifer pollution.

Resumo: Um dos principais impactos ambientais causados por aterros de resíduos sólidos é a contaminação de aquíferos, que ocorre quando os lixiviados dos resíduos sólidos atingem esse meio. A água subterrânea alterada pelos lixiviados passa, ao longo do tempo e espaço, por diversos processos biogeoquímicos que são responsáveis pela formação de diferentes zonas redox no meio ambiente subterrâneo. Essas zonas-redox condicionam o comportamento das diversas substâncias oriundas do próprio lixiviado e outras que resultam da interação entre a água subterrânea, lixiviado e meio geológico. Algumas dessas substâncias podem causar riscos à saúde humana e a receptores ecológicos. Assim, o entendimento do comportamento dessas substâncias em subsuperfície é fundamental para o estabelecimento de medidas de intervenção ambiental que visem a recuperação de áreas com depósitos de resíduos sólidos. Neste contexto este trabalho tem como objetivo apresentar uma revisão de trabalhos existentes sobre: (a) mecanismos de formação e composição do lixiviado; e (b) ambientes biogeoquímicos e composição de águas subterrâneas impactadas por lixiviados. Este tema é pertinente no sentido de que a Política Nacional de Resíduos Sólidos prevê a erradicação de todos os lixões e aterros controlados no Brasil até 2014, bem como a realização investigações visando a recuperação destes locais.

Palavras Chaves: Resíduos sólidos; aterros; biogeoquímica; poluição de aquíferos.

\section{INTRODUÇÃO}

A disposição adequada de resíduos sólidos é relativamente recente no Mundo. Segundo Kehew (2001), até a década de 1960 os resíduos sólidos eram dispostos de maneira inadequada, uma vez que raros eram os levantamentos prévios efetuados a respeito da hidrogeologia local e poucas precauções eram tomadas a fim de proteger o meio ambiente.

No ano de 2008 foram produzidas no território brasileiro cerca de 183 mil toneladas diárias de resíduos urbanos, dos quais $20 \%$ foi depositado em vazadouros a céu aberto (lixões), 20\% em aterros controlados e $58 \%$ em aterros sanitários (BRASIL, 2011a). Levantamento do IBGE (2010) aponta que aproximadamente $51 \%$ dos municípios ainda depositam os resíduos urbanos em lixões. Além disso, são diversos os relatos sobre a ocorrência de problemas ambientais associados a aterros sanitários ou controlados com problemas de construção e/ou operação (CHRISTENSEN et al.,

\footnotetext{
${ }^{1}$ Regea Geologia e Estudos Ambientais. (carlos@ regea.com.br)

${ }^{2}$ IGc USP. (bertolo@usp.br)
} 
2001; BJERG et al., 2003; CHRISTENSON e COZZARELLI, 2003; HYPOLITO e EZAKI, 2006; LAGO, ELIS e GIACHETI, 2006; MONDELLI et al., 2007; LOPES, BRIGANTE e SCHALCH, 2007; MOURA, 2008, BORTOLIN e MALAGUTI FILHO, 2010). Assim, persistem impactos negativos decorrentes tanto de depósitos recentes mal executados, quanto de depósitos antigos que ainda não passaram por intervenções ambientais adequadas.

Um dos principais impactos ambientais causados pela deposição inadequada de resíduos sólidos é a contaminação das águas subterrâneas, que passa ao longo do tempo e espaço, por diversos processos biogeoquímicos que variam conforme as características do lixiviado e da hidrogeologia local. Os processos biogeoquímicos são responsáveis pela formação de diferentes zonas redox no meio ambiente subterrâneo, e que condicionam o comportamento das diversas substâncias oriundas do próprio lixiviado e do substrato geológico. Algumas destas substâncias são potencialmente causadoras de riscos à saúde humana e a receptores ecológicos locais.

Desta maneira, o entendimento dos processos que ocorrem nas águas subterrâneas impactadas pelo líquido lixiviado oriundo da disposição de resíduos sólidos é fundamental para o estabelecimento de medidas de intervenção ambiental que visem a recuperação dessas áreas impactadas.

Neste contexto, este artigo tem como foco principal apresentar uma revisão de trabalhos existentes sobre os processos biogeoquímicos que ocorrem no interior de aquíferos impactados por lixiviados oriundos de aterros de resíduos sólidos. Devido à importância da constituição do lixiviado nesses processos, também são apresentadas considerações sobre os mecanismos de formação e composição do lixiviado.

A apresentação deste tema é oportuna, uma vez que a Política Nacional de Resíduos Sólidos prevê a erradicação de todos os lixões e aterros controlados no Brasil até 2014, além da realização investigações visando a recuperação e monitoramento destes locais (BRASIL, 2010).

\section{MECANISMOS DE FORMAÇÃO DO LIXIVIADO}

Segundo a NBR 15849 (ABNT, 2010), o lixiviado é definido como o "líquido resultante da infiltração de águas pluviais no maciço de resíduos, da umidade dos resíduos e da água de constituição de resíduos orgânicos liberada durante sua decomposição no corpo do aterro sanitário". Segundo Souto (2009) o termo percolado não se aplica para esta definição, uma vez que a percolação é a simples passagem de um líquido através de um meio poroso, sem implicar no arraste (lixiviação) de substâncias por esse líquido.

A degradação dos resíduos para a formação do lixiviado é resultado da combinação de processos físico-químicos, químicos e biológicos que atuam no interior do aterro. Os processos biológicos são dominantes e muitas vezes regulam os demais processos (BAEDECKER e BACK, 1979a,b; MCBEAN et al., 1995).

Os processos físico-químicos ocorrem por contato e arraste mecânico pela água. Os processos de sorção e difusão são os principais mecanismos que envolvem o contato entre os resíduos sólidos e o líquido. Segundo Souto (2009) a degradação por processos químicos envolve as alterações promovidas por uma série de eventos que ocorrem no interior do maciço de resíduos, tais como reações redox (ou de óxi-redução), dissolução, precipitação e complexação.

Os processos biológicos envolvem a ação de microorganismos de diversos grupos, e os produtos do metabolismo de um grupo podem servir de fonte de alimento para outros grupos (SOUTO, 2009). Os grupos de microorganismos presentes variam no tempo de acordo com as diversas fases pelas quais passa $\mathrm{o}$ aterro.

Fatores como o clima, o relevo, os tipos de resíduos depositados, a forma de operação e o tempo de maturação dos aterros justificam a diferença entre lixiviados de diferentes aterros. Sob determinadas condições, as características hidrogeológicas e hidrogeoquímicas locais também são importantes na formação do lixiviado.

Distintas condições de precipitação, evapotranspiração e temperatura afetam a qualidade e quantidade do lixiviado produzido em uma determinada área. Em regiões onde a precipitação supera a evapotranspiração ocorre uma maior produção relativa de lixiviado. Nas épocas de maior pluviosidade, Pohland e Harper (1985) indicam que po- 
dem ocorrer menores concentrações de substâncias no lixiviado devido à diluição pela maior infiltração de água da chuva. Em regiões de clima tropical é esperado que as concentrações de substâncias no lixiviado sejam maiores que aquelas encontradas em lixiviados gerados em regiões de clima temperado, função da maior atividade biológica sob condições mais quentes (CHEN, 1996).

A posição no relevo onde está situado o aterro também pode afetar a produção do lixiviado, uma vez que propicia maior ou menor entrada de água no sistema. Assim, em aterros situados em terrenos cujo relevo propicie maior infiltração, haverá maior produção de lixiviado.

Nos casos em que o lixo foi depositado sob o nível d'água (como antigas lagoas, por exemplo), as características hidrogeológicas e hidrogeoquímicas locais influenciam na quantidade e qualidade do lixiviado na medida em que também existe contribuição de água do subsolo para o interior da massa de resíduos.

Os tipos de resíduos depositados influenciam principalmente na composição do lixiviado. Destaca-se nesse sentido, a importância da eventual presença de resíduos industriais na massa de resíduos, conforme ressalta Kehew (2001).
Segundo Souto (2009) a forma de operação do aterro possui influência nas características do lixiviado. $\mathrm{O}$ autor destaca as seguintes características: o número e disposição das células de aterramento, a topografia do aterro, a impermeabilização da base, a compactação das células, a relação área exposta/volume, a profundidade do aterro, a localização e extensão da frente de trabalho, o tipo de cobertura das células, a qualidade do sistema de drenagem de águas pluviais e a existência e características do sistema de recirculação de lixiviado.

O tempo de maturação influencia na qualidade e na quantidade do lixiviado produzido pelo aterro, e para o entendimento dessas variações, a evolução de um aterro foi dividida em fases, que marcam as diversas mudanças nos processos biogeoquímicos que se processam em seu interior. Essas fases são descritas no item a seguir.

\section{Fases dos aterros}

Diversos estudos têm sido realizados com o objetivo de melhor compreender as fases de um aterro ao longo do tempo, as consequências nos processos biogeoquímicos que ocorrem em seu interior, bem como a sua influência nas características dos lixiviados formados. Pohland e Harper

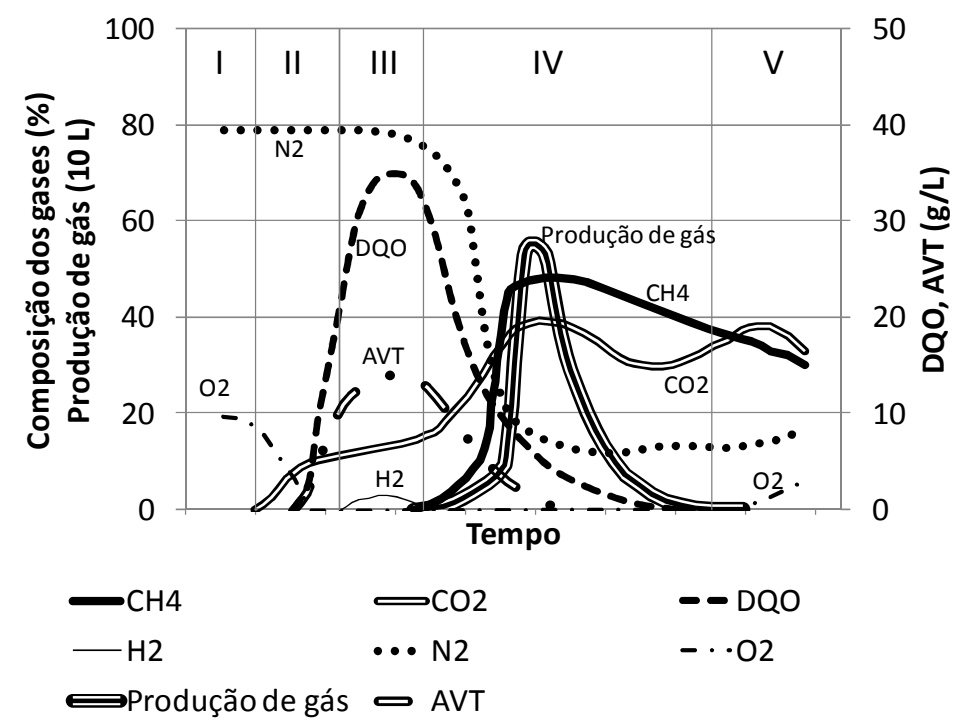

Figura 1 - Fases do aterro segundo modelo de Pohland e Harper (1985).

Figure 1 - Pohland and Harper (1985) model of landfill phases. 
(1985), por exemplo, dividem em cinco as fases do aterro (Figura 1).

Este modelo é utilizado por muitos autores (ITRC, 2006; LOPES e CONDE, 2008; SOUTO, 2009, dentre outros). Souto (2009) ressalva que este modelo tem como deficiência a suposição de que o aterro é preenchido e coberto de uma vez só. As fases descritas nesse modelo são as seguintes:

$\checkmark \quad$ Fase I - Aeróbia: fase curta que ocorre até que a capacidade de campo dos resíduos seja atingida e o oxigênio disponível comece a ser consumido por bactérias aeróbias;

$\checkmark \quad$ Fase II - Transição: nesta fase é iniciada a instalação de condições anaeróbias. Ocorre aumento da demanda química de oxigênio (DQO) e dos ácidos voláteis totais (AVT). As bactérias fermentativas promovem a hidrólise da matéria orgânica e formação de ácidos, álcoois e dióxido de carbono (CO2);

$\checkmark \quad$ Fase III - Acidogênese: ocorre o desaparecimento do oxigênio. São formados ácidos carboxílicos (incluindo ácido acético), hidrogênio (H2) e $\mathrm{CO} 2$ pelas bactérias acidogênicas que se alimentam dos produtos do metabolismo das bactérias aeróbias. O nitrogênio tende a passar para a forma amoniacal devido à ausência de oxigênio. A presença de ácidos orgânicos reduz o $\mathrm{pH}$ e eleva os valores de DBO (demanda bioquímica de oxigênio) e DQO. Metais pesados e outras substâncias inorgânicas passam para a fase dissolvida devido ao baixo pH. Como o ácido acético é uma das principais substâncias formadas nessa fase, alguns autores, como FANIN e ROBERTS (2006) denominam essa fase de Acetogênica;

$\checkmark \quad$ Fase IV - Metanogênese: nesta fase ocorre a formação de metano e dióxido de carbono a partir do ácido acético e hidrogênio, por meio da ação de microorganismos metanogênicos, que consomem os ácidos, que continuam a ser produzidos pelas bactérias acidogênicas. Assim, embora a produção de ácidos continue, suas concentrações no aterro diminuem em relação à fase anterior, uma vez que passam a ser consumidos. Os valores de DBO e DQO começam a baixar pela redução das concentrações desses ácidos e outros compostos orgânicos facilmente biodegradáveis. A razão DBO/DQO também é reduzida porque a DQO reduz proporcionalmente menos que a $\mathrm{DBO}$, pois alguns dos principais parâmetros que contribuem para a DQO (como ácidos húmicos e fúlvicos e alguns íons) são menos biodegradáveis que aqueles que compõem a DBO. Como os ácidos passam a formar metano e o nitrogênio dissolvido continua formar nitrogênio amoniacal, o pH aumenta. Com o aumento do $\mathrm{pH}$ ocorre precipitação de metais pesados que estavam em fase dissolvida anteriormente. $\mathrm{O}$ tempo para o aterro atingir a fase metanogênica estável varia de alguns meses a décadas, pois depende de um grande crescimento dos microorganismos metanogênicos que devem consumir os ácidos orgânicos voláteis que continuam sendo produzidos pelas bactérias acidogênicas. Assim, alguns autores, como Souto (2009), defendem que a metanogênese deve ser dividida em fase metanogênica instável e fase metanogênica estável. Segundo Mcbean et al. (1995) o início da fase metanogênica estável ocorre mais rapidamente quando existe maior conteúdo de água e vazão do lixiviado. Em países de clima temperado a transição para a fase metanogênica estável é de cerca de 4 a 5 anos (MCBEAN et al., 1995), enquanto em países de clima tropical é esperado um processo mais rápido. Chen (1996) verificou que essa fase era alcançada em um prazo máximo de 1,5 anos em nove aterros de Taiwan;

Fase V - Maturação: esta fase ocorre depois que os materiais orgânicos facilmente degradáveis são consumidos para a formação de metano e dióxido de carbono, promovendo uma queda abrupta na formação de biogás. O lixiviado tende a um pH em torno de 7 e são reduzidas as concentrações de substâncias orgânicas e inorgânicas dissolvidas no lixiviado.

Fanin e Roberts (2006) apresentam o tempo de duração das diversas fases descritas anteriormente e os principais processos biogeoquímicos ocorrentes (Tabela 1). Souto (2009) ainda destaca que, como os aterros normalmente apresentam muitos anos de operação, é comum a ocorrência de simultaneidade de diversas fases. Os resíduos recém dispostos, normalmente localizados próximos à superfície estão submetidos a processos aeróbios, enquanto aqueles localizados em camadas mais antigas e profundas estão na fase metanogênica ou até mesmo estabilizados. Por existir contínuo alimento proveniente das camadas superiores, é possível que a microbiota das camadas profundas sobreviva mais, em função da degradação das cama- 
Tabela 1 - Duração das fases dos aterros de resíduos sólidos domiciliares e respectivos processos biogeoquímicos predominantes.

Table 1 - Phases of domestic landfills and predominant biogeochemical processes.

\begin{tabular}{lll}
\hline Fase [1] & Processo biogeoquímico [2] & Duração [2] \\
\hline I Aeróbia & Hidrólise e degradação (ambiente aeróbio) & Horas a dias \\
II Transição & Hidrólise e fermentação (ambiente anaeróbio) & Dias a semanas \\
III Acidogênese & Acetogênese (ambiente anaeróbio) & 6 a 18 meses \\
IV Metanogênese & Metanogênese (ambiente anaeróbio) & Anos a décadas \\
V Maturação & Oxidação & \\
\hline [1] Pohland e Harper (1985); [2] Fanin e Roberts (2006). &
\end{tabular}

das mais recentes do que daquela ocorrida em suas proximidades. Como a camada de base está na fase metanogênica, o lixiviado drenado nas camadas inferiores seria característico daquele da fase metanogênica, mesmo que ocorram deposições recentes no aterro.

Há autores que realizam subdivisões mais simplificadas das fases dos aterros, voltadas para aspectos práticos do tratamento dos lixiviados. Fanin e Roberts (2006) dividem as fases dos aterros em três: (a) Fase ácida (aterro jovem); (b) Fase metanogênica (aterro velho); e (c) Fase de maturação (aterro estabilizado). Essa divisão é de mais fácil utilização quando da interpretação de resultados de análises de lixiviados ou mesmo águas impactadas por esses produtos. No tratamento de lixiviados, Souto (2009) destaca que eles podem ser classificados simplesmente como lixiviados novos ou velhos. Não há a necessidade de se classificar possíveis "lixiviados intermediários" porque os períodos de transição são normalmente curtos. Mcbean et al. (1995) afirmam que os lixiviados novos são de mais fácil tratamento, uma vez que por apresentarem carga orgânica elevada são facilmente degradáveis.

\section{Composição do lixiviado}

Considerando um aterro comum (predominantemente domiciliar, mas contendo algum resíduo industrial), segundo Christensen et al. (2001), as substâncias com potencial de contaminação presentes no lixiviado podem ser agrupadas em:

Matéria orgânica dissolvida: expressa co- mo demanda de oxigênio (DBO ou DQO) ou carbono orgânico total, incluindo CH4, ácidos orgânicos voláteis (particularmente nas fases ácidas dos aterros) e compostos mais refratários (como ácidos húmicos e fúlvicos). Incluem também alguns compostos orgânicos complexos, como estrógenos e medicamentos;

$\checkmark \quad$ Macrocomponentes inorgânicos: $\mathrm{Ca} 2+$, $\mathrm{Mg} 2+, \mathrm{Na}+, \mathrm{K}+, \mathrm{NH} 4+, \mathrm{Fe} 2+, \mathrm{Mn} 2+, \mathrm{Cl}-, \mathrm{SO} 42-$, e $\mathrm{HCO} 3-;$

$\checkmark \quad$ Metais pesados: $\mathrm{Cd}, \mathrm{Cr}, \mathrm{Cu}, \mathrm{Pb}, \mathrm{Ni}$ e $\mathrm{Zn}$. Além dessas, outras espécies como B, As, Se, Ba, Li, Hg e Co também são encontradas em lixiviados, porém em menores concentrações;

$\checkmark \quad$ XOCs (compostos orgânicos xenobióticos) como hidrocarbonetos aromáticos, fenóis e clorados (usualmente $<1 \mathrm{mg} / \mathrm{L}$ ).

Diversos estudos avaliaram a composição de lixiviados em várias partes do mundo; Öman e Junestedt (2008) detectaram a ocorrência de mais de 90 substâncias orgânicas (incluindo diversos XOCs) e 50 substâncias inorgânicas em lixiviados de 12 aterros municipais de resíduos na Suécia; Baun e Christensen (2004) apresentam concentrações médias de alguns parâmetros constituintes de lixiviados de aterros de 7 países (Alemanha, Dinamarca, França, Hong Kong, Holanda, Reino Unido e USA); Baun et al. (2004) constataram a ocorrência de XOCs em lixiviados de 10 aterros municipais na Dinamarca; Kjeldsen et al. (2002) apresentam uma revisão de trabalhos relacionados a composições de lixiviados novos e muito antigos (mais de 30 anos); Ehrig $(1983,1988)$ compilou 
dados da composição do lixiviado, possibilitando a diferenciação dos lixiviados da fase ácida e da fase metanogênica; e, Pohland e Harper (1985) apresentam uma lista extensa de parâmetros encontrados em lixiviados em diversas fases. A Tabela 2 apresenta uma compilação de informações disponibilizadas em Pohland e Harper (1985) e Ehrig (1983, 1988).

Tabela 2 - Composição do lixiviado em fase ácida, metanogênica e maturação. Todos os valores em mg/L exceto $\mathrm{pH}$, relação $\mathrm{DBO} / \mathrm{DQO}$ e metano.

Table 2 - Composition of leachate in acid, methanogenic and maturation phases. All values in mg/L except $\mathrm{pH}$, electric conductivity, DBO/DQO and methane.

\begin{tabular}{|c|c|c|c|}
\hline Parâmetro & Fase ácida & Fase metanogênica & Fase de maturação \\
\hline $\mathrm{pH}$ & 4,7 a 7,7 & 6,3 a 8,8 & 7,1 a 8,8 \\
\hline Cond. Eletr. $(\mu \mathrm{S} / \mathrm{cm})$ & 1.600 a 17.000 & 2.900 a 7.700 & 1.400 a 4500 \\
\hline ORP $(\mathrm{mV})$ & 80 a -240 & -70 a -240 & 97 a 163 \\
\hline Ácidos voláteis & 3.000 a 18.000 & 250 a 4.000 & Ausente \\
\hline $\mathrm{DBO}$ & 1.000 a 57.700 & 600 a 3.400 & 4 a 120 \\
\hline DQO & 1500 a 71.100 & 580 a 9.760 & 31 a 900 \\
\hline DBO/DQO & 0,4 a 0,8 & 0,17 a 0,64 & 0,02 a 0,13 \\
\hline NTK & 14 a 1970 & 25 a 82 & 7 a 490 \\
\hline Nitrogênio amoniacal & 2 a 1.030 & 6 a 430 & 6 a 430 \\
\hline Nitrato & 0,05 a 19 & ausente & 0,5 a 0,6 \\
\hline Fosfato & 0,2 a 120 & 0,7 a 14 & 0,2 a 14 \\
\hline Alcalinidade & 140 a 9.650 & 760 a 5.050 & 200 a 3.520 \\
\hline $\mathrm{Fe}$ & 90 a 2.200 & 115 a 336 & 4 a 20 \\
\hline $\mathrm{Mn}$ & 0,6 a 41 & 0,6 & 0,6 \\
\hline $\mathrm{K}$ & 35 a 2.300 & 35 a 2.300 & 35 a 2.300 \\
\hline $\mathrm{Na}$ & 20 a 7.600 & & \\
\hline $\mathrm{Ca}^{*}$ & 10 a 2500 & 20 a 600 & \\
\hline $\mathrm{Mg}$ & 3 a 1.140 & 81 a 505 & 81 a 190 \\
\hline $\mathrm{Cl}$ & 30 a 5.000 & 30 a 5.000 & 30 a 5.000 \\
\hline $\mathrm{SO} 4$ & 10 a 3.240 & Ausente & 5 a 40 \\
\hline S2- & 0 a 818 & 0,9 & ausente \\
\hline CH4 (no ar) & $<0,01$ & 0,30 a 0,60 & 0 a 0,10 \\
\hline $\mathrm{Cd}^{*}$ & 0,005 & 0,005 & \\
\hline $\mathrm{Pb}^{*}$ & 0,09 & 0,09 & \\
\hline $\mathrm{Cr}^{*}$ & 0,28 & 0,28 & \\
\hline $\mathrm{Co}^{*}$ & 0,05 & 0,05 & \\
\hline $\mathrm{Ni}^{*}$ & 0,17 & 0,17 & \\
\hline $\mathrm{Zn}^{*}$ & 0,1 a 120 & 0,03 a 4 & \\
\hline $\mathrm{Cu}^{*}$ & 0,07 & 0,07 & \\
\hline
\end{tabular}

Fonte: Pohland e Harper (1985), exceto onde indicado com * (EHRIG, 1988) 
Estudos que apresentam as características composicionais de lixiviados de aterros brasileiros são raros. Entre as existentes são destaques as de Ferreira et al. (2001), Giordano (2003), do Departamento de Química da Universidade Federal do Paraná (UFPR, 2012) e as de Souto (2009). Dos estudos levantados, apenas Souto (2009) preparou tabelas diferenciando lixiviados em fases ácida e metanogênica, Os dados composicionais obtidos por esse autor estão sintetizadas na Tabela 3.

Comparando os dados de Ehrig (1983,
1988), representativos de lixiviados de aterros em clima temperado, com aqueles obtidos para o Brasil, Souto (2009) constatou que os lixiviados brasileiros apresentam: maiores amplitudes de variação de $\mathrm{pH}$, alcalinidade total, $\mathrm{DBO}, \mathrm{DQO}$ e fósforo total, independentemente da fase do aterro; além de apresentarem menores concentrações de nitrogênio amoniacal; maiores concentrações de cloreto; e menores concentrações de metais durante a fase ácida e maiores durante a fase metanogênica.

Tabela 3 - Composição de lixiviados de aterros brasileiros em fases ácidas e metanogênicas. Todas as unidades em $\mathrm{mg} / \mathrm{L}$, exceto $\mathrm{pH}$, turbidez, condutividade elétrica e coliformes totais.

Table 3 - Composition of brazilian leachate in acid and methanogenic phases. All values in mg/L except pH, turbidity, electric conductivity and total coliform.

\begin{tabular}{|c|c|c|c|c|c|c|}
\hline \multirow[t]{2}{*}{ Parâmetro } & \multicolumn{3}{|c|}{ Fase Ácida } & \multicolumn{3}{|c|}{ Fase Metanogênica } \\
\hline & Variação & $20 \%-80 \% *$ & $\operatorname{Ref} * *$ & Variação & $20 \%-80 \% *$ & $\operatorname{Ref} * *$ \\
\hline $\mathrm{pH}$ & $4,4-8,4$ & $5,1-8,3$ & 13 & $5,9-9,2$ & $7,1-8,7$ & 32 \\
\hline Alcalinidade total & $170-32000$ & $460-25000$ & 7 & $125-20200$ & $425-11900$ & 19 \\
\hline Turbidez (UNT) & $100-540$ & & 1 & $0,02-620$ & $6-540$ & 11 \\
\hline Cond. Eletr. $(\mu \mathrm{S} / \mathrm{cm})$ & $230-45000$ & & 4 & $100-45000$ & $2520-25600$ & 23 \\
\hline DBO & $1-55000$ & $35-25400$ & 12 & $3-17200$ & $60-6000$ & 30 \\
\hline DQO & $90-100000$ & $540-53700$ & 13 & $20-35000$ & $700-13500$ & 34 \\
\hline Nitrogênio Total Kjeldahl & $1,7-3000$ & & 4 & $0,6-5000$ & $90-3000$ & 13 \\
\hline Nitrogênio Amoniacal & $0,07-2000$ & $10-1800$ & 9 & $0,03-3000$ & $50-2400$ & 29 \\
\hline Nitrato & nd -45 & & 3 & nd -270 & nd - 60 & 15 \\
\hline Fósforo & nd - 260 & nd - 107 & 5 & nd - 80 & $0,2-40$ & 19 \\
\hline Cloreto & $275-4700$ & & 2 & $20-6900$ & $330-4100$ & 17 \\
\hline Sólidos totais & $400-45000$ & $1000-39300$ & 7 & $200-29000$ & $1450-19100$ & 23 \\
\hline Sólidos totais Voláteis & $78-26700$ & $260-21800$ & 6 & $75-20000$ & $600-8700$ & 20 \\
\hline Sólidos totais Fixos & $40-28400$ & & 4 & $100-17000$ & $900-12300$ & 15 \\
\hline Sólidos Suspensos Totais & $10-7000$ & & 4 & $7-12400$ & $15-2600$ & 17 \\
\hline $\mathrm{Fe}$ & nd -1400 & $0,004-500$ & 8 & $0,01-720$ & $0,4-80$ & 19 \\
\hline $\mathrm{Cd}$ & nd - 0,1 & nd $-0,09$ & 7 & nd - 0,6 & nd - 0,1 & 19 \\
\hline $\mathrm{Cu}$ & nd $-0,8$ & nd $-0,5$ & 7 & nd $-2,9$ & nd - 1,1 & 17 \\
\hline $\mathrm{Cr}$ & nd - 1,2 & nd - 0,6 & 5 & nd - 1,0 & $0,006-0,8$ & 19 \\
\hline $\mathrm{Mn}$ & nd - 115 & & 4 & nd - 30 & $0,025-10$ & 14 \\
\hline $\mathrm{Ni}$ & nd $-6,5$ & & 4 & nd - 1,4 & nd $-0,8$ & 14 \\
\hline $\mathrm{Zn}$ & nd - 27 & nd -7 & 7 & nd -35 & $0,01-2$ & 21 \\
\hline $\mathrm{Pb}$ & nd $-1,5$ & nd $-1,3$ & 6 & nd $-6,7$ & nd $-1,1$ & 18 \\
\hline Coliformes totais (NMP/100 mL) & $200-5 E+7$ & & 1 & nd $-2 E+8$ & $1,6-2 E+7$ & 10 \\
\hline
\end{tabular}




\section{ÁGUAS SUBTERRÂNEAS ASSOCIADAS A ATERROS DE RESÍDUOS SÓLIDOS}

Embora a qualidade da água subterrânea em regiões onde estão instalados aterros de resíduos seja frequentemente monitorada, são escassos os estudos que detalham os processos hidrogeoquímicos que ocorrem nessas áreas (KEHEW, 2001).

Entre os estudos melhor documentados, são destaques os executados em aterros dos seguintes países:

EUA: Army Creek - Baedecker \& Back (1979a, 1979b); e Norman - Cozzarelli et al. (2000); Zume, Tarhule \& Christenson (2006); Lorah, Cozzarelli \& Bohlke (2009); Cozzarelli et al. (2011);
Canadá: Borden - Nicholson, Cherry \& Reardon (1983); McFarlane et al. (1983);

$\checkmark \quad$ Dinamarca: Vejen - Lyngkilde \& Christensen (1992a, 1992b); Heron \& Christensen (1995); Baun et al., (2003); Grindsted - Bjerg et al. (1995); Heron et al., (1998); Sjoelund - Tuxen et al. (2003, 2006); Bjerg et al. (2009); Holanda: Banisveld Roling et al. (2001); van Breukelen et al. (2003); van Breukelen (2003).

A Tabela 4 apresenta algumas informações relacionadas com estes e com outros aterros que foram objetos de estudos hidrogeoquímicos. A análise destas informações permite afirmar que:

Tabela 4 - Características de aterros e contaminantes identificados nas águas subterrâneas.

Table 4 - Characteristics of landfills and substances found in groundwater.

(continua)

\begin{tabular}{|c|c|c|c|c|}
\hline $\begin{array}{l}\text { Aterro, } \\
\text { Cidade, } \\
\text { País, } \\
\text { Referência } \\
\end{array}$ & $\begin{array}{l}\text { Período, Área, } \\
\text { Extensão da } \\
\text { pluma e } \\
\text { Clima [1] }\end{array}$ & $\begin{array}{l}\text { Tipo de resíduo e Méto- } \\
\text { do de disposição }\end{array}$ & $\begin{array}{l}\text { Contexto geológico- } \\
\text { geomorfológico }\end{array}$ & $\begin{array}{l}\text { Contaminantes identifi- } \\
\text { cados na água subterrâ- } \\
\text { nea }\end{array}$ \\
\hline $\begin{array}{l}\mathrm{BV}, \mathrm{BI} \\
\text { Mar del Plata } \\
\text { Argentina } \\
{[2],[3]}\end{array}$ & $\begin{array}{l}1979-2001^{*} \\
0,63 \mathrm{~km}^{2} \\
600 \mathrm{~m} \\
\mathrm{Cfb} \\
\end{array}$ & $\begin{array}{l}\text { Resíduo domiciliar em } \\
\text { lixão, e depois em aterro } \\
\text { sanitário. }\end{array}$ & $\begin{array}{l}\text { Siltes e areias sobre } \\
\text { quartzitos em colina. } \\
\text { Prof. nível d'água (NA) } \\
\text { entre } 5 \text { e } 15 \mathrm{~m} \text {. }\end{array}$ & Inorgânicos, Zn \\
\hline $\begin{array}{l}\text { El Akader } \\
\text { Irbid } \\
\text { Jordânia } \\
{[4]}\end{array}$ & $\begin{array}{l}1981-2001 * \\
0,60 \mathrm{~km}^{2} \\
>4 \mathrm{~km} \\
\text { BSh }\end{array}$ & $\begin{array}{l}\text { Efluentes e resíduos } \\
\text { sólidos domiciliares e } \\
\text { industriais em lixão }\end{array}$ & $\begin{array}{l}\text { Areias sobre calcário em } \\
\text { colinas e planícies. NA } \\
\text { entre } 300 \text { e } 450 \mathrm{~m} .\end{array}$ & $\begin{array}{l}\text { Inorgânicos, metais pesa- } \\
\text { dos }\end{array}$ \\
\hline $\begin{array}{l}\text { Atenas } \\
\text { Atenas } \\
\text { Grécia } \\
{[5]}\end{array}$ & $\begin{array}{l}1971-1991 \\
- \\
>1000 \mathrm{~m} \\
\text { Csa }\end{array}$ & $\begin{array}{l}\text { Resíduo domiciliar em } \\
\text { aterro sanitário }\end{array}$ & $\begin{array}{l}\text { Calcário em relevo cársti- } \\
\text { co }\end{array}$ & $\begin{array}{l}\text { Inorgânicos, metais pesa- } \\
\text { dos }\end{array}$ \\
\hline $\begin{array}{l}\text { Norman } \\
\text { Oklahoma } \\
\text { USA } \\
{[6]-[11]} \\
\end{array}$ & $\begin{array}{l}1922-1985 \\
0,18 \mathrm{~km}^{2} \\
200 \mathrm{~m} \\
\mathrm{Cfa} \\
\end{array}$ & $\begin{array}{l}\text { Resíduo domiciliar em } \\
\text { lixão até } 1960 \text { posterior- } \\
\text { mente aterro em valas }\end{array}$ & $\begin{array}{l}\text { Areias, siltes e cascalhos } \\
\text { sobre folhelhos em planí- } \\
\text { cie aluvial. NA de } 0 \text { a } 4 \text { m }\end{array}$ & $\begin{array}{l}\text { Inorgânicos, metais pesa- } \\
\text { dos, XOCs, matéria } \\
\text { orgânica dissolvida }\end{array}$ \\
\hline $\begin{array}{l}\text { Pirana } \\
\text { Ahmadabad } \\
\text { Índia } \\
{[12]}\end{array}$ & $\begin{array}{l}1988-2008 * \\
0,34 \mathrm{~km}^{2} \\
- \\
\text { BSh }\end{array}$ & Resíduo domiciliar & $\begin{array}{l}\text { Areias, argilas e casca- } \\
\text { lhos em planície aluvial. } \\
\text { NA menor que } 2 \mathrm{~m} \text {. }\end{array}$ & $\begin{array}{l}\text { Inorgânicos, metais pesa- } \\
\text { dos }\end{array}$ \\
\hline $\begin{array}{l}\text { Banisveld } \\
\text { Boxtel } \\
\text { Holanda } \\
{[13]-[15]} \\
\end{array}$ & $\begin{array}{l}1965-1977 \\
0,06 \mathrm{~km}^{2} \\
120 \mathrm{~m} \\
\text { BSh } \\
\end{array}$ & $\begin{array}{l}\text { Resíduo domiciliar em } \\
\text { lixão }\end{array}$ & $\begin{array}{l}\text { Argilas arenosas inconso- } \\
\text { lidadas em planície. NA a } \\
2 \mathrm{~m} .\end{array}$ & $\begin{array}{l}\text { Macrocomponentes } \\
\text { inorgânicos, metais pesa- } \\
\text { dos, XOCs }\end{array}$ \\
\hline $\begin{array}{l}\text { Grindsted } \\
\text { Grindsted } \\
\text { Dinamarca } \\
{[6],[16],[17]} \\
\end{array}$ & $\begin{array}{l}1930-1977 \\
0,10 \mathrm{~km}^{2} \\
200 \mathrm{~m} \\
\text { Dfb } \\
\end{array}$ & $\begin{array}{l}\text { Domiciliar, industrial, } \\
\text { lodo de ETE, resíduos de } \\
\text { demolição em aterro } \\
\text { sanitário }\end{array}$ & $\begin{array}{l}\text { Areias com camadas } \\
\text { argilosas em planície } \\
\text { glacial. NA entre } 0 \text { e } 3 \mathrm{~m}\end{array}$ & $\begin{array}{l}\text { Inorgânicos, metais pesa- } \\
\text { dos, XOCs, matéria } \\
\text { orgânica dissolvida }\end{array}$ \\
\hline $\begin{array}{l}\text { Vejen } \\
\text { Vejen } \\
\text { Dinamarca } \\
{[18]-[22]}\end{array}$ & $\begin{array}{l}1962-1981 \\
0,06 \mathrm{~km}^{2} \\
350 \mathrm{~m} \\
\text { Dfb }\end{array}$ & $\begin{array}{l}\text { Domiciliar, industrial e de } \\
\text { demolição em lixão em } \\
\text { antiga cava }\end{array}$ & $\begin{array}{l}\text { Areias sobre argila em } \\
\text { planície glacial. Água } \\
\text { subterrânea percolando o } \\
\text { lixo }\end{array}$ & $\begin{array}{l}\text { Inorgânicos, metais pesa- } \\
\text { dos, XOCs, matéria } \\
\text { orgânica dissolvida }\end{array}$ \\
\hline $\begin{array}{l}\text { Sant'Agostino } \\
\text { Ferrara } \\
\text { Itália } \\
\text { [23] }\end{array}$ & $\begin{array}{l}1987-2006 \\
0,80 \mathrm{~km}^{2} \\
- \\
\mathrm{Cfa}\end{array}$ & $\begin{array}{l}\text { Resíduo domiciliar em } \\
\text { aterro em valas (1987- } \\
\text { 1991) e aterro sanitário } \\
(1991-2006)\end{array}$ & $\begin{array}{l}\text { Argila siltosa, turfa e } \\
\text { lentes arenosas em planí- } \\
\text { cie deltaica. NA de } 2 \text { a } 5 \\
\mathrm{~m}\end{array}$ & $\begin{array}{l}\text { Inorgânicos, metais pesa- } \\
\text { dos }\end{array}$ \\
\hline
\end{tabular}


Tabela 4 - Características de aterros e contaminantes identificados nas águas subterrâneas.

Table 4 - Characteristics of landfills and substances found in groundwater.

\begin{tabular}{|c|c|c|c|c|}
\hline $\begin{array}{l}\text { Aterro, } \\
\text { Cidade, } \\
\text { País, } \\
\text { Referência }\end{array}$ & $\begin{array}{l}\text { Período, } \\
\text { Área, Exten- } \\
\text { são da pluma } \\
\text { e } \\
\text { Clima [1] }\end{array}$ & $\begin{array}{l}\text { Tipo de resíduo e } \\
\text { Método de disposição }\end{array}$ & $\begin{array}{l}\text { Contexto geológico- } \\
\text { geomorfológico }\end{array}$ & $\begin{array}{l}\text { Contaminantes iden- } \\
\text { tificados na água } \\
\text { subterrânea }\end{array}$ \\
\hline $\begin{array}{l}\text { Mérida } \\
\text { Mérida } \\
\text { México } \\
{[24]}\end{array}$ & $\begin{array}{l}1981-1999 * \\
0,38 \mathrm{~km}^{2} \\
100 \mathrm{~m} \\
\text { Aw }\end{array}$ & $\begin{array}{l}\text { Resíduos industriais e } \\
\text { domiciliares em lixão }\end{array}$ & $\begin{array}{l}\text { Calcário em relevo } \\
\text { cárstico. NA em } 5 \text { m }\end{array}$ & $\begin{array}{l}\text { Inorgânicos, metais } \\
\text { pesados, coliformes }\end{array}$ \\
\hline $\begin{array}{l}\text { Tha Muang } \\
\text { Bangkok } \\
\text { Tailândia } \\
\text { [24] }\end{array}$ & $\begin{array}{l}1970-1999 * \\
0,01 \mathrm{~km}^{2} \\
500 \mathrm{~m} \\
\text { Aw }\end{array}$ & $\begin{array}{l}\text { Resíduos domiciliares } \\
\text { em lixão }\end{array}$ & $\begin{array}{l}\text { Depósitos arenosos em } \\
\text { planície aluvial. NA } \\
\text { raso }\end{array}$ & $\begin{array}{l}\text { Inorgânicos, metais } \\
\text { pesados, coliformes }\end{array}$ \\
\hline $\begin{array}{l}\text { Mai Hia } \\
\text { Chiang Mai } \\
\text { Tailândia } \\
{[24]}\end{array}$ & $\begin{array}{l}\sim 1959-1989 \\
0,12 \mathrm{~km}^{2} \\
1000 \mathrm{~m} \\
\text { Aw }\end{array}$ & $\begin{array}{l}\text { Resíduos domiciliares } \\
\text { em lixão }\end{array}$ & $\begin{array}{l}\text { Areias com cascalhos e } \\
\text { siltes em meia encosta. } \\
\text { NA entre } 3 \text { e } 4 \mathrm{~m}\end{array}$ & $\begin{array}{l}\text { Inorgânicos, metais } \\
\text { pesados, coliformes }\end{array}$ \\
\hline $\begin{array}{l}\text { Astrolab Park } \\
\text { Sydnei } \\
\text { Austrália } \\
{[25]}\end{array}$ & $\begin{array}{l}1973-1991(?) \\
0,04 \mathrm{~km}^{2} \\
150 \mathrm{~m} \\
\mathrm{Cfb}\end{array}$ & $\begin{array}{l}\text { Resíduos domiciliares } \\
\text { em lixão em antiga } \\
\text { cava de exploração de } \\
\text { areia }\end{array}$ & $\begin{array}{l}\text { Areias com lentes de } \\
\text { silte e argila em colina. } \\
\text { Lixo dentro do aquífe- } \\
\text { ro. }\end{array}$ & $\begin{array}{l}\text { Inorgânicos, metais } \\
\text { pesados }\end{array}$ \\
\hline $\begin{array}{l}\text { Borden } \\
\text { Waterloo } \\
\text { Canadá } \\
{[26],[27]}\end{array}$ & $\begin{array}{l}1940-1976 \\
0,05 \mathrm{~km}^{2} \\
700 \mathrm{~m} \\
\text { Dfb }\end{array}$ & $\begin{array}{l}\text { Resíduos domiciliares e } \\
\text { de construção em aterro } \\
\text { em vala (até 1973) }\end{array}$ & $\begin{array}{l}\text { Areias sobre argilas e } \\
\text { siltes em colina. Água } \\
\text { subterrânea percolando } \\
\text { o lixo. }\end{array}$ & $\begin{array}{l}\text { Inorgânicos, matéria } \\
\text { orgânica dissolvida }\end{array}$ \\
\hline $\begin{array}{l}\text { San Giuliano } \\
\text { Veneza } \\
\text { Itália } \\
{[28]}\end{array}$ & $\begin{array}{l}1945-2001^{*} \\
0,11 \mathrm{~km}^{2} \\
- \\
\mathrm{Cfa}\end{array}$ & $\begin{array}{l}\text { Resíduos industriais e } \\
\text { domiciliares em aterro } \\
\text { sanitário }\end{array}$ & $\begin{array}{l}\text { Argilas sobre areias } \\
\text { siltosas em planície de } \\
\text { maré. NA entre } 0 \text { e } 2 \mathrm{~m} \text {. }\end{array}$ & $\begin{array}{l}\text { Inorgânicos, matéria } \\
\text { orgânica dissolvida }\end{array}$ \\
\hline $\begin{array}{l}\text { Army Creek } \\
\text { Delaware } \\
\text { USA } \\
{[29],[30]}\end{array}$ & $\begin{array}{l}1960-1968 \\
0,24 \mathrm{~km}^{2} \\
700 \mathrm{~m} \\
\mathrm{Cfa}\end{array}$ & $\begin{array}{l}\text { Resíduos industriais e } \\
\text { domiciliares em lixão } \\
\text { em cava submersa de } \\
\text { areia }\end{array}$ & $\begin{array}{l}\text { Areias e cascalhos } \\
\text { sobre argilas em colina. } \\
\text { Lixo dentro do aquífe- } \\
\text { ro. }\end{array}$ & $\begin{array}{l}\text { Inorgânicos, matéria } \\
\text { orgânica dissolvida }\end{array}$ \\
\hline $\begin{array}{l}\text { Taubaté } \\
\text { Taubaté, SP } \\
\text { Brasil } \\
{[31]}\end{array}$ & $\begin{array}{l}1979-1984 * \\
0,06 \mathrm{~km}^{2} \\
200 \mathrm{~m} \\
\text { Cwa }\end{array}$ & $\begin{array}{l}\text { Resíduos industriais e } \\
\text { domiciliares em aterro } \\
\text { sanitário }\end{array}$ & $\begin{array}{l}\text { Areias e argilas em } \\
\text { colina. NA entre } 1 \mathrm{e} \\
2 \mathrm{~m} .\end{array}$ & $\begin{array}{l}\text { Inorgânicos, matéria } \\
\text { orgânica dissolvida }\end{array}$ \\
\hline
\end{tabular}

* - aterros em operação quando da publicação do trabalho

** - climas segundo classificação de Koppen-Geiger: Cfb - Maritimo da costa ocidental; BSh - Seco; Csa - Mediterrâneo; Cfa - Subtropical úmido; Dfb - Continental úmido; Cfa - Subtropical úmido; Aw - Tropical úmido; Cwa - Subtropical úmido Fontes: [1] Peel, Finlayson, e McMahon (2007); [2] Bocanegra et al. (2001); [3] Martinez et al. (2003); [4] Abu-Rukah e AlKofahi (2001); [5] Loizidou e Kapetanios (1993); [6] Bjerg et al. (2003); [7] Christenson e Cozzarelli (2003); [8] Cozzarelli et al. (2000); [9] Lorah, Cozzarelli e Böhlke (2009); [10] Zume, Tarhule, e Christenson (2006); [11] Cozzarelli et al. (2011); [12] Singh et al. (2008); [13] Roling (2001); [14] Van Breukelen et al. (2003); [15] Van Breukelen (2003); [16] Heron et al. (1998); [17] Bjerg et al. (1995); [18] Lyngkilde e Christensen (1992); [19] Lyngkilde e Christensen (1992); [20] Heron e Christensen (1995); [21] Brun et al. (2002); [22] Baun et al. (2003); [23] Rapticaputo e Vaccaro (2006); [24] Klinck e Stuart (1999); [25]Jorstad, Jankowski e Acworth (2004); [26] Nicholson, Cherry e Reardon (1983); [27] Macfarlane et al. (1983); [28] Critto, Carlon, Marcomini (2003); [29] Baedecker e Back (1979a); [30] Baedecker e Back (1979b); [31] Parisot et al. (1985)

a) águas subterrâneas contaminadas por depósitos de resíduos sólidos ocorrem tanto associadas a lixões, quanto a aterros sanitários. Esse fato, já registrado em alguns estudos por Bjerg et al. (2003) e Christenson e Cozzarelli (2003), está rela- cionado provavelmente a problemas construtivos nos aterros sanitários;

b) a maior parte das publicações relacionadas a impactos causados a água subterrânea por aterros 
sanitários está concentrada na Europa e América do Norte, onde predominam climas temperados;

c) as principais substâncias de interesse identificadas nas águas subterrâneas em decorrência da presença de depósitos de resíduos são macrocomponentes inorgânicos e matéria orgânica dissolvida, função do monitoramento em relação a estes compostos. A presença de XOCs, que são pouco analisados, foi constatada por Kjeldsen e Christophersen (2001) na grande maioria das campanhas de monitoramento de água subterrânea realizados em 106 aterros predominantemente domiciliares na Dinamarca;

d) apenas dois dos 17 aterros relacionados na Tabela 4 apresentaram plumas com extensões superiores a $1000 \mathrm{~m}$ de extensão, sendo esses dois casos associados a plumas em aquíferos cársticos. Plumas com extensão inferiores a $1000 \mathrm{~m}$ foram também notadas por Christensen et al. (2001) com base na análise de estudos executados em 18 aterros de resíduos predominantemente domiciliares sobre aquíferos porosos no Canadá, Dinamarca, Alemanha, Holanda e Estados Unidos;

e) todos os aterros listados foram avaliados alguns anos após o seu início. Nenhum dos trabalhos foi efetuado com aterros em fase ácida.

\section{Ambientes geoquímicos em aquíferos impacta- dos por lixiviados}

Fetter (1999) resume os ambientes geoquímicos nos aquíferos associados a um aterro de resíduos sólidos da seguinte forma: à montante do aterro, o aquífero frequentemente apresenta condições aeróbicas; sob o aterro, e em suas proximidades imediatas, o aquífero passa a apresentar condições anaeróbicas devido ao total consumo do oxigênio pela oxidação da matéria orgânica; a jusante do aterro, na medida em que a pluma formada pelo aterro se distancia deste, um novo ambiente geoquímico se forma gradualmente, passando para um ambiente de transição até retornar para um ambiente aeróbico novamente. Os ambientes sob o aterro e os de transição formados à jusante do aterro caracterizam-se por uma sequência de zonas redox que Christensen et al. (2001) esquematizaram como apresentado na Figura 2. Essas zonas foram sugeridas por Baedecker e Back (1979a, 1979b) e Nicholson et al. (1983) e confirmadas por Lyngkilde e Christensen (1992a), Bjerg et al. (2003) entre outros. A identificação dessas zonas é fundamental para o entendimento do comportamento das substâncias dissolvidas em águas subterrâneas impactadas por lixiviado.

As principais reações redox que ocorrem na água subterrânea impactada por lixiviado, segundo Christensen et al. (2001), são as apresentadas na Tabela 5.

Tabela 5 - Principais reações redox em aquíferos impactados por lixiviado. Matéria orgânica dissolvida está representada pelo composto $\mathrm{CH}_{2} \mathrm{O}$. OMO = Oxidação da Matéria Orgânica.

Table 5 - Most important redox reactions in aquifers impacted by landfill leachates. Dissolved organic matter is represented by $\mathrm{CH}_{2} \mathrm{O}$. OMO is Organic Matter Oxidation.

\begin{tabular}{ll}
\hline Processos redox & Reações \\
\hline Metanogênese/ Mineralização fermentativa da mat. org. & $2 \mathrm{CH}_{2} \mathrm{O} \rightarrow \mathrm{CH}_{3} \mathrm{COOH} \rightarrow \mathrm{CH}_{4}+\mathrm{CO}_{2}$ \\
Redução do sulfato/ OMO & $2 \mathrm{CH}_{2} \mathrm{O}+\mathrm{SO}_{4}{ }^{2-}+\mathrm{H}^{+} \rightarrow 2 \mathrm{CO}_{2}+\mathrm{HS}^{-}+2 \mathrm{H}_{2} \mathrm{O}$ \\
Redução do ferro/ OMO & $\mathrm{CH}_{2} \mathrm{O}+4 \mathrm{Fe}(\mathrm{OH})_{3}+8 \mathrm{H}^{+} \rightarrow \mathrm{CO}_{2}+4 \mathrm{Fe}^{2+}+11 \mathrm{H}_{2} \mathrm{O}$ \\
Redução do manganês/ OMO & $\mathrm{CH}_{2} \mathrm{O}+2 \mathrm{MnO}_{2}+4 \mathrm{H}^{+} \rightarrow \mathrm{CO}_{2}+2 \mathrm{Mn}^{2+}+3 \mathrm{H}_{2} \mathrm{O}$ \\
Denitrificação/ OMO & $5 \mathrm{CH}_{2} \mathrm{O}+4 \mathrm{NO}_{3}^{-}+4 \mathrm{H}^{+} \rightarrow \mathrm{CO}_{2}+2 \mathrm{~N}_{2}+7 \mathrm{H}_{2} \mathrm{O}$ \\
Respiração aeróbia & $\mathrm{CH}_{2} \mathrm{O}+\mathrm{O}_{2} \rightarrow \mathrm{CO}_{2}+\mathrm{H}_{2} \mathrm{O}$ \\
Redução do CO2 & $\mathrm{HCO}_{3}+\mathrm{H}^{+}+4 \mathrm{H}_{2} \rightarrow \mathrm{CH}_{4}+3 \mathrm{H}_{2} \mathrm{O}$ \\
Oxidação do amônio & $\mathrm{NH}_{4}^{+}+2 \mathrm{O}_{2} \rightarrow \mathrm{NO}_{3}^{-}+2 \mathrm{H}^{+}+\mathrm{H}_{2} \mathrm{O}$ \\
Oxidação do metano & $\mathrm{CH}_{4}+2 \mathrm{O}_{2} \rightarrow \mathrm{HCO}_{3}^{-}+\mathrm{H}^{+}+\mathrm{H}_{2} \mathrm{O}$ \\
\hline
\end{tabular}

Fonte: Christensen et al. (2001) 
A Figura 2 mostra a disposição das seis zonas redox em pluma originada a partir do impacto causado pelo lixiviado sobre as águas subterrâneas. São reconhecidas as seguintes zonas: metanogênica, sulfato-redutora, ferro-redutora, manganês-redutora, de denitrificação e aeróbia. Essas zonas, ao longo da linha de fluxo, se tornam mais oxidantes com o distanciamento do aterro na mesma proporção em que ocorre a atenuação do carbono orgânico dissolvido (DOC).
Nas proximidades do aterro, na região da zona metanogênica, ocorre a formação de gás carbônico, metano e amônio (pela degradação de aminoácidos e proteínas) e gás sulfídrico (pela redução do sulfato). O ferro (III) e Mn (IV) em fase sólida são mantidos em baixas quantidades, pois uma parte significativa destas espécies é solubilizada em ambiente redutor (CHRISTENSEN et al., 2001).

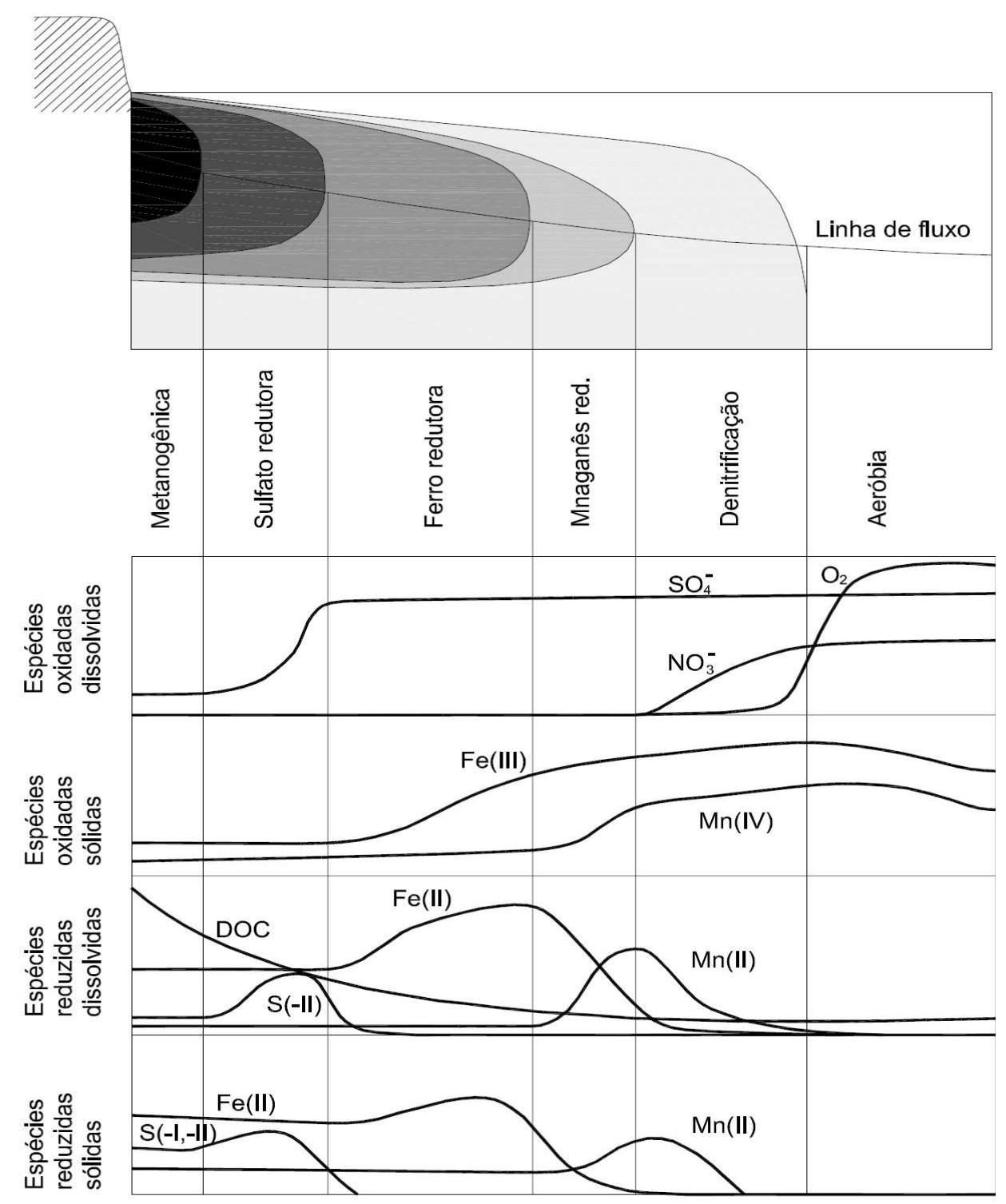

Figura 2 - Zonas redox formadas em um aquífero originalmente aeróbio impactado por um aterro em fase metanogênica e a distribuição das espécies químicas sensíveis às alterações nas condições redox. Fonte: Christensen et al. (2001).

Figure 2 - Schematic redox zonation in an originally aerobic aquifer downgradient from a landfill in methanogenic phase, and the distribution of redox-sensitive species. Source: Christensen et al. (2001). 
Com o distanciamento do aterro e retorno às condições oxidantes (devido à presença de $\mathrm{O}_{2}$ dissolvido na água subterrânea das bordas da pluma de contaminação) e consequente aumento do $\mathrm{Eh}$, o $\mathrm{Fe}(\mathrm{II})$ e $\mathrm{Mn}$ (II) dissolvidos se oxidam e precipitam; outros metais pesados podem ser imobilizados junto a esses minerais. $\mathrm{O}$ nitrogênio amoniacal se oxida e gera nitrato, que juntamente com o cloreto permanecem no aquífero por serem estáveis nessas condições geoquímicas (CHRISTENSEN et al., 2001).

As principais fontes de informação passíveis de utilização para identificação das zonas redox são a composição das águas subterrâneas, do material aquífero e das populações microbiológicas nestes meios. Lyngkilde e Christensen (1992a) desenvolveram critérios para identificação destas zonas com base na composição das águas subterrâneas. Estes critérios, elaborados com base em resultados obtidos no Aterro Vejen (Dinamarca), são apresentados na Tabela 6.

$\mathrm{O}$ modelo representado na Figura 2 e Tabela 6 é bastante simplificado, uma vez que o zoneamento geoquímico pode ser bastante afetado pelas heterogeneidades hidrogeológicas e geoquímicas locais. Neste contexto, Heron et al. (1998) demonstraram que as variações de pequena escala, indicadas por levantamentos geológicos e geoquímicos de detalhe, podem vir a ser muito importantes para o entendimento dos processos geoquímicos ocorrentes no aquífero. Em áreas contaminadas, o conhecimento destas variações apresenta especial importância, uma vez que é fundamental a distinção dos impactos causados pelas plumas de contaminação das variações geoquímicas naturais do aquífero.

Ademais, investigações realizadas em algumas localidades, como no Aterro Grindsted (BJERG et al., 1995) mostram que os processos redox indicados na Figura 2 não ocorrem individualmente no tempo e espaço, sendo predominante a ocorrência de mais de uma reação simultaneamente.

Heron e Christensen (1995), comparando resultados de aterros na Dinamarca, Canadá e Estados Unidos, também verificaram que algumas zonas redox não são observadas em alguns aterros. Porém Christensen et al. (2001) sugerem que quanto mais detalhado for o estudo do aterro, maior é o número de zonas redox identificadas, ainda que alguns aspectos poderiam implicar na ausência da formação de uma ou mais zonas redox.

O modelo representado na Figura 2 representa uma condição em que o aterro se encontra em fase metanogênica e a população de microorganismos do aquífero já está equilibrada com a carga orgânica oriunda do lixiviado. Essa condição é representativa da maior parte do tempo de um aquífero impactado por lixiviado de resíduos sólidos. Entretanto, até que seja atingida essa condição, é esperado que ocorram ambientes distintos dentro do aquífero, sendo o inicial aquele formado em decorrência do impacto de um lixiviado novo. Nesse ambiente inicial é esperado que se façam presentes as reações de acetogênese e ausentes as reações de metanogênese, bem como o transporte de metais pesados.

Tabela 6 - Critérios para identificação de zonas redox em águas subterrâneas impactadas por lixiviados. Valores em mg/L. Table 6 - Criteria for identification of redox zones in leachate plumes of contamination. Values in mg/L.

\begin{tabular}{lcccccc}
\hline \multirow{2}{*}{ Substância } & \multicolumn{5}{c}{ Zonas Redox } \\
\cline { 2 - 6 } & Aeróbia & Denitrificação & $\begin{array}{c}\text { Manganês } \\
\text { redutora }\end{array}$ & $\begin{array}{c}\text { Ferro } \\
\text { redutora }\end{array}$ & $\begin{array}{c}\text { Sulfato } \\
\text { redutora }\end{array}$ & Metanogênica \\
\hline Oxigênio & $>1,0$ & $<1,0$ & $<1,0$ & $<1,0$ & $<1,0$ & $<1,0$ \\
Nitrato & & $<0,2$ & $<0,2$ & $<0,2$ & $<0,2$ \\
Nitrito & $<0,1$ & $<0,1$ & $<0,1$ & $<0,1$ & $<0,1$ \\
Amônio & $<0,1$ & $<0,2$ & $>0,2$ & & & \\
Mn(II) & $<0,2$ & $<1,5$ & $<1,5$ & $>1,5$ & & $<40,0$ \\
Fe(II) & $<1,5$ & & & & & $>1,0$ \\
Sulfato & $<0,1$ & $<0,1$ & $<0,1$ & $<0,1$ & $>0,2$ & $<1,0$ \\
Sulfeto & $<1,0$ & $<1,0$ & $<1,0$ & $<1,0$ & & \\
Metano & & & & & & \\
\hline
\end{tabular}

Fonte: Lyngkilde \& Christensen (1992). 
As reações de acetogênese no interior do aquífero antes da produção de metano (e a persistência dos produtos dessas reações por até 2 anos) já foram constatadas em aquíferos recém impactados por combustíveis (FREITAS et al., 2010).

A formação e extensão das zonas redox na pluma de contaminação estão diretamente relacionadas às características do lixiviado, às características físicas e geoquímicas do aquífero, bem como a cinética das reações. Entre as características físicas do aquífero, destacam-se os seguintes aspectos: $\checkmark \quad$ a velocidade da água subterrânea: são esperadas plumas mais extensas em aquíferos de elevados gradientes e condutividades hidráulicos;

$\checkmark \quad$ o tipo de aquífero: a clara definição das zonas redox é mais esperada em aquíferos granulares. Em aquíferos fraturados, a atenuação por reações redox são limitadas, uma vez que as zonas dependentes de condições aeróbias podem não ocorrer devido ao pouco contato das águas destes aquíferos com a atmosfera (CHRISTENSEN et al., 2001). Esse é um dos fatores que segundo Murray et al. (1981) poderiam explicar a longa pluma formada a jusante do aterro de Kohl Spring. Entre os outros fatores pode-se citar a baixa dispersão em fluxos no interior de aquíferos fraturados;

a geometria, anisotropias e heterogeneidades do aquífero representam um aspecto importante na forma da pluma de contaminação, na medida que condicionam as linhas de fluxo, bem como a maior ou menor dispersão lateral da pluma. A irregularidade do topo rochoso é destacada por Barbosa e Otero (1999) como importante fator que pode promover alterações no sentido do fluxo subterrâneo.

Entre as principais características geoquímicas do aquífero associadas à extensão e a forma de ocorrência da zona redox são destaques as seguintes:

$\checkmark$ Capacidade de Troca Catiônica (CTC): uma vez que indica a capacidade do solo de reter determinados íons, como metais pesados e macrocomponentes catiônicos (DEUTSH, 1997). Usualmente a CTC está relacionada à quantidade de argila, matéria orgânica natural e de óxidos e hidróxidos (APPELO e POSTMA, 2005);
Capacidade de oxidação do aquífero (COX): uma vez que regula o processo de degradação da matéria orgânica. Ou seja, são esperadas menores plumas em aquíferos de alta COX. Em alguns casos, aquíferos com elevada COX podem comprometer a formação de zonas metanogênicas e sulfato-redutoras (BARBOSA e OTERO, 1999). A COX pode ser calculada, considerando água e sólidos, com base na seguinte equação (BARCELONA e HOLM, 1991):

$\mathrm{COX}=4\left[\mathrm{O}_{2}\right]+5\left[\mathrm{NO}_{3}{ }^{-}\right]+\left[\mathrm{Fe}(\mathrm{III})_{\mathrm{d}}\right]+2\left[\mathrm{Mn}(\mathrm{IV})_{\mathrm{d}}\right]+8\left[\mathrm{SO}_{4}{ }^{2-}\right]+4\left[\mathrm{CH}_{2} \mathrm{O}\right]$ (Equação 1)

Dentre estas substâncias, são destaques os óxidos e hidróxidos de ferro móveis na fase sólida e o sulfato e o nitrato dissolvido na água subterrânea, que podem agir como receptores de elétrons transferidos durante a degradação microbiana de matéria orgânica (CHRISTENSON e COZZARELLI, 2003; HERON et al., 1998).

$\checkmark \quad$ Concentração de carbono orgânico na fase sólida: uma vez que promove a sorção de substâncias orgânicas não polares, como alguns XOCs (SCHWARZENBACH e WESTALL, 1981).

Alguns destes parâmetros geoquímicos foram utilizados por Heron et al. (1998) para caracterizar o substrato geológico do Aterro de Grindsted e correlacioná-lo com as zonas redox encontradas nas águas subterrâneas locais.

\section{Componentes biogeoquímicos de aquíferos im- pactados por lixiviados}

Christensen et al (2001) subdividem os componentes biogeoquímicos das águas subterrâneas impactadas por lixiviados em microbiológicos, matéria orgânica dissolvida, macrocomponentes inorgânicos, metais pesados e compostos orgânicos xenobióticos. Esses componentes, que devem fazer parte dos planos de monitoramento de água subterrânea nestes empreendimentos, sofrem alterações ao longo das linhas de fluxo e das zonas redox por processos físicos (diluição e dispersão hidrodinâmica), físico-químicos (sorção e volatilização), químicos (complexação, precipitação, dissolução e troca iônica) e bioquímicos (degradação). 
A diluição devido à recarga do aquífero e à dispersão hidrodinâmica são processos comuns a todos os componentes, ocorrendo quando da mistura do lixiviado com a água subterrânea. Para algumas substâncias não reativas, como o cloreto, estes processos são os únicos que promovem a atenuação da contaminação. A diluição varia de acordo com as características construtivas do aterro, do lixiviado (viscosidade e densidade) e do aquífero (dispersividade) (CHRISTENSEN et al., 2001). Os demais processos ocorrentes são descritos a seguir para cada componente biogeoquímico principal.

\section{Componentes microbiológicos}

As populações microbianas de aquíferos impactados por lixiviados são muito distintas (em quantidade, composição e atividade) daquelas encontradas em aquíferos não poluídos (LUDVIGSEN et al., 1999, ROLING et al., 2001). Essa diferença ocorre devido à presença de espécies químicas reduzidas e as altas concentrações de matéria orgânica no lixiviado (BJERG et al., 2003). Essas condições não são encontradas nos aquíferos rasos mais comuns, que são normalmente aeróbios e oligotróficos.

Nos aquíferos impactados por lixiviados, as populações microbianas são dominadas por bactérias, como demonstrado por Ludvigsen et al. (1999) por meio de análises de PLFA (determinação de ácidos graxos). A densidade destes organismos está em uma faixa de $4 \times 10^{4}$ a $1 \times 10^{9}$ célu$\mathrm{las} / \mathrm{g}$ (peso seco), e o número de unidades formadoras de colônias (UFC) entre 10 e $1 \mathrm{E}+7 \mathrm{UFC} / \mathrm{g}$ nestes aquíferos impactados (CHRISTENSEN et $a l ., 2001)$. A grande variação destes números está relacionada aos tipos de aquíferos analisados e métodos analíticos utilizados. Segundo Jager et al. (1989) não existem grandes diferenças entre aterros domiciliares e hospitalares no que se refere a concentrações de bactérias na água subterrânea.

A composição da população microbiana também varia ao longo dos diversos ambientes redox encontrados a partir do aterro, e é fundamental para a formação da sequência desses ambientes. Entre os trabalhos que relacionaram esses ambientes e as populações encontradas são destaques os desenvolvidos nos aterros de Grindsted (LUDVIGSEN et al., 1999), Banisveld (ROLING et al., 2001; VAN BREUKELEN, 2003) e Norman
(WEISS e COZZARELLI, 2008). Roling et al. (2001), por meio de análises de DNA, reportam a ocorrência de bactérias denitrificadoras (Azoarcus e Actinobacteria) e ferro oxidantes (G. ferruginea) à montante do aterro de Banisveld. Sob o aterro foram encontrados microorganismos fermentativos (como membros Clostridiaceae) e da família $\mathrm{Ge}$ obacteraceae. Imediatamente a jusante do aterro, onde predominavam condições ferro-redutoras, as bactérias da família Geobacteraceae foram relatadas como cerca de $22 \%$ do total. Bactérias com potencial de denitrificaçao (Azoarcus) e de sulfato redução foram identificadas à jusante do aterro. $\mathrm{O}$ estudo da microbiologia de aquíferos é complexo devido à dificuldade de obtenção de dados das bactérias existentes pelos métodos de análise disponíveis. Métodos envolvendo culturas de microorganismos detectam menos de $1 \%$ do total da comunidade microbiológica existente. Atualmente, abordagens de biologia molecular, incluindo sequenciamento de DNA e tecnologia microarray (biochip de DNA), constituem novas ferramentas que estão sendo utilizadas com sucesso na geração de informação sobre composição, quantidade e atividade da população microbiológica (WEISS e COZZARELLI, 2008). Ainda assim, estes autores recomendam que os estudos de identificação de ambientes redox e degradação de contaminantes, sejam realizados por uma abordagem multidisciplinar envolvendo técnicas geoquímicas e microbiológicas.

\section{Matéria orgânica dissolvida}

A matéria orgânica dissolvida na água subterrânea é normalmente expressa por parâmetros como carbono orgânico total e dissolvido (TOC e DOC) e as demandas química e bioquímica de oxigênio (DQO e DBO). O DOC é composto por vários produtos da degradação da matéria orgânica, desde pequenos ácidos voláteis até ácidos fúlvicos e húmicos, além do metano. Sua composição varia conforme a fase do aterro, ocorrendo aumento proporcional da concentração de compostos de maior massa molar (> $1000 \mathrm{~g} / \mathrm{mol}$ ) sobre os de menor massa molar quando atingida a fase metanogênica (CHRISTENSEN et al., 2001), dado que os compostos de menor massa molar são mais suscetíveis a volatilização para formação do metano. 
As concentrações de DOC no lixiviado são centenas de vezes maiores do que em águas subterrâneas não contaminadas (BAEDECKER e APGAR, 1984). Assim, quando o lixiviado entra em contato com a água subterrânea é esperado que o oxigênio dissolvido seja rapidamente consumido (ROSE e LONG, 1988). Com efeito, é a elevada carga de matéria orgânica a responsável pela criação do ambiente fortemente redutor na água subterrânea, de grande capacidade de doação de elétrons, que por sua vez gera os diversos ambientes redox formados a partir do aterro.

Os principais processos que regulam a atenuação das concentrações do carbono orgânico dissolvido são diluição por recarga, dispersão e degradação (CHRISTENSEN et al., 2001). Kjeldsen e Christensen (1984), por meio de experimento de coluna, verificaram que o DOC é transportado quase à mesma velocidade da água subterrânea, indicando que o processo de sorção deste parâmetro é praticamente desprezível. Christensen et al. (2001), entretanto, destacam a ausência de trabalhos baseados em observações de campo que confirmassem esses dados de laboratório.

A atenuação por volatilização do DOC ocorre apenas pela formação de metano, uma vez que este parâmetro é altamente volátil. Desta forma, a liberação do metano a partir da água subterrânea alterada por lixiviado pode ser tão significante que pode ser utilizada para fins de delimitação de plumas (CHRISTENSEN et al., 2001).

\section{Macrocomponentes iônicos}

Os macrocomponentes iônicos, ou íons maiores, envolvem as espécies químicas encontradas em elevadas concentrações na água subterrâ- nea, tais como cloreto, bicarbonato, sulfato, cálcio, magnésio, potássio, sódio, amônio, ferro e manganês.

A maior parte destas espécies químicas não possui toxicidade elevada, ainda que existam limites de potabilidade para algumas delas. Alguns desses componentes são importantes, entretanto, por controlar ambientes redox e atenuar metais pesados. Entre os íons mais problemáticos, o amônio é importante por ser um nutriente tóxico para espécies aquáticas (ERSKINE, 2000; CHRISTENSEN et al., 2001). As concentrações desse íon no lixiviado costumam ser superiores a $100 \mathrm{mg} / \mathrm{L}$ por décadas (POHLAND e HARPER, 1985, EHRIG, 1988; KJELDSEN et al., 2002) e o valor de referência máximo aceitável para lançamento de efluentes para nitrogênio amoniacal, é de $20 \mathrm{mg} / \mathrm{L} \mathrm{N}$ (BRASIL, 2011).

Os principais processos de atenuação dos íons maiores são, além da diluição e dispersão, processos redox, troca iônica e precipitação. Além destes, podem ocorrer processos de complexação com matéria orgânica, que promovem o aumento da mobilidade destes parâmetros, e dissolução de sólidos do material do aquífero, que promovem aumento de concentrações (CHRISTENSEN, 2001). A Tabela 7 resume os prováveis processos geoquímicos de maior importância que controlam o comportamento dos íons maiores nas águas subterrâneas impactadas por lixiviados.

O cloreto é um ânion de destaque, uma vez que praticamente não sofre reações químicas. Este parâmetro é considerado conservativo, sofrendo apenas os processos físicos de diluição e dispersão. $\mathrm{O}$ bicarbonato/carbonato apresenta, juntamente com a pressão de $\mathrm{CO}_{2}$, elevadas concentrações em

Tabela 7 - Principais processos geoquímicos que controlam o comportamento dos macrocomponentes iônicos em águas subterrâneas impactadas por lixiviados

Table 7 - Main geochemical processes affecting the behavior of the ionic macrocomponents in leachate plumes.

\begin{tabular}{|c|c|c|c|c|c|c|c|c|c|c|}
\hline \multirow[b]{2}{*}{ Processos } & \multicolumn{3}{|c|}{ Ânions } & \multicolumn{7}{|c|}{ Cátions } \\
\hline & $\mathrm{Cl}^{-}$ & $\begin{array}{c}\mathrm{HCO}_{3}{ }^{-} \\
\mathrm{CO}_{3}{ }^{2-}\end{array}$ & $\mathrm{SO}_{4}{ }^{2-}$ & $\mathrm{Ca}^{2+}$ & $\mathrm{Mg}^{2+}$ & $\mathrm{Na}^{+}$ & $\mathrm{K}^{+}$ & $\mathrm{NH}_{4}^{+}$ & $\begin{array}{l}\mathrm{Fe}^{2+} \\
\mathrm{Fe}^{3+}\end{array}$ & $\begin{array}{l}\mathrm{Mn}^{2+} \\
\mathrm{Mn}^{4+}\end{array}$ \\
\hline Diluição/dispersão & + & + & + & + & + & + & + & + & + & + \\
\hline Complexação & - & + & $(+)$ & + & + & - & - & - & $(+)$ & $(+)$ \\
\hline Processos redox & - & - & + & - & - & - & - & $(+)$ & + & + \\
\hline Troca iônica & - & - & $(+)$ & + & + & + & + & + & + & + \\
\hline Precipitação/ dissolução & - & + & - & + & + & - & - & - & + & + \\
\hline
\end{tabular}

+: importante; (+) usualmente de menor importância; -: não importante

Fonte: Christensen et al., 2001. 
lixiviados de aterros na fase metanogênica, devido aos processos de dissolução e decomposição no aterro (CHRISTENSEN e KJELDSEN, 1989). Assim, estes íons são fundamentais na formação de complexos e precipitados com $\mathrm{Ca}, \mathrm{Mg}, \mathrm{Fe}$ e $\mathrm{Mn}$ e alguns metais pesados. A determinação da alcalinidade é fundamental para a realização de interpretações hidroquímicas. Entretanto, a sua determinação em águas impactadas por lixiviados pode ser afetada pela presença de substâncias orgânicas (acetatos, propionatos e buriatos) que aceitam prótons durante a titulação (CHRISTENSEN et al., 2001), o que pode dificultar a determinação das concentrações de bicarbonato e carbonato.

$\mathrm{O}$ sulfato ocorre geralmente em baixas concentrações em aquíferos impactados por lixiviados, uma vez que é esperado que o enxofre ocorra principalmente na forma reduzida como sulfeto, tanto como gás sulfídrico como minerais metálicos (p.ex. o ferro na pirita - HERON e CHRISTENSEN, 1995). Baixas concentrações de sulfato foram encontradas em alguns aterros como Army Creek (BAEDECKER e BACK, 1979a) e Norman (CHRISTENSON e COZZARELLI, 2003) na área impactada por carbono orgânico dissolvido. Entretanto, em aterros como Borden (NICHOLSON et al. 1983) e Grindsted (KJELDSEN et al., 1998), importantes concentrações de sulfato foram encontradas e relacionadas com a presença de resíduos de construção civil (gesso) no aterro e com a possível lenta cinética de reação do sulfato, condicionada pela ocorrência de óxidos de ferro que limitavam a extensão de ambientes mais reduzidos na pluma. Por outro lado, o enxofre também pode ser encontrado na matriz do aquífero como enxofre nativo, tal como observado em Borden (NICHOLSON et al., 1983).

Os principais processos geoquímicos que controlam o comportamento dos cátions dissolvidos nas águas subterrâneas impactadas por lixiviados são diluição, troca catiônica e precipitação/ dissolução (Tabela 7). Processos redox também controlam o amônio, ferro e manganês.

Christensen et al. (2001) relacionam os seguintes comportamentos para os cátions maiores: (a) Potássio: possui alta afinidade por troca catiônica, além de também poder ser irreversivelmente adsorvido em argilominerais; (b) Sódio: possui menor afinidade por locais de troca, sendo menos intensamente atenuado por troca catiônica e permanecendo predominantemente em solução; (c) Cálcio: possui alta afinidade por locais de troca, porém devido à sua normalmente elevada concentração, muitas vezes é encontrado movendo-se junto com a frente da pluma. O cálcio forma complexos com carbonatos e DOC e participa de reações de dissolução e precipitação de calcita, mineral neoformado comum em ambientes dominados pela metanogênese; (d) Magnésio: possui alta afinidade por locais de troca, e tem geoquímica semelhante ao do cálcio, participando de reações de precipitação e dissolução; (e) Amônio: tem forte afinidade por sítios de adsorção, sendo sua mobilidade fortemente influenciada por reações de troca catiônica. É também rapidamente atenuado por reações de nitrificação em ambientes oxidantes (ERSKINE, 2000 e CHRISTENSEN et al. 2001); (f) Ferro e Manganês: são controlados por uma série de processos, incluindo redox, troca catiônica, precipitação de sulfetos e carbonatos e, possivelmente, complexação com carbono orgânico dissolvido, ocorrendo em maiores concentrações quando o aterro encontra-se na fase ácida.

\section{Metais pesados}

Os metais pesados, como As, $\mathrm{Cd}, \mathrm{Ni}, \mathrm{Zn}$, $\mathrm{Cu}, \mathrm{Hg}$ e $\mathrm{Pb}$, não constituem um problema frequente em aterros de resíduos sólidos domiciliares, parte porque os resíduos geralmente contém baixas concentrações desses metais e parte porque estes metais são sujeitos a forte atenuação por sorção e precipitação na fase metanogênica do aterro (ERSKINE, 2000; CHRISTENSEN et al., 2001). Conforme destaca Souto (2009), as concentrações de metais pesados são significativamente inferiores em aterros domiciliares quando comparados com aterros industriais. Na fase ácida do aterro, mesmo nos aterros domiciliares, são esperadas maiores concentrações de íons metálicos devido à maior mobilidade desses parâmetros em pH mais baixo.

A maior preocupação com a mobilidade de metais pesados na fase metanogênica está relacionada à formação de complexos porque, uma vez complexados, os metais pesados normalmente adquirem maior mobilidade. Diversos autores (JENSEN e CHRISTENSEN, 1999; BAUN et al. 2004; LI et al. 2009) ressaltam que a maior parte dos metais pesados estão na fração coloidal (tama- 
nho entre 0,001 e $0,45 \mu \mathrm{m}$ ) e em complexos orgânicos e inorgânicos dissolvidos. Segundo Baun et al. (2004), os íons livres perfazem geralmente menos de $30 \%$ do total das concentrações dos metais no lixiviado (na maior parte das vezes, menos de $10 \%)$. Assim, para a compreensão do comportamento de metais pesados é importante o conhecimento de sua especiação nas fases sólidas (particulado e coloidal) e na água (como complexos orgânicos, inorgânicos e íons livres). Para a fração dissolvida, o entendimento da formação de complexos tem sido bastante favorecidos pelo uso de modelos matemáticos como o PhreeqC (PARKHURST e APPELO, 1999) e o Minteq (ALLISON et al., 1991).

A atenuação por sorção dos metais ocorre principalmente em minerais argilosos, matéria orgânica e óxidos de ferro e manganês. A adsorção do metal dissolvido é regulada pelo $\mathrm{pH}$ do meio, sendo que a taxa de adsorção para os cátions metálicos aumenta com a elevação do pH (CHRISTENSEN et al., 2001). O padrão inverso ocorre com os ânions metálicos, como o cromo hexavalente e o arsênio trivalente e pentavalente. A atenuação dos metais pesados por precipitação ocorre principalmente em sulfetos e carbonatos, ainda que fosfatos e hidróxidos possam contribuir para a redução da solubilidade. Nesse sentido, a maior parte dos metais pesados não passa pela zona sulfato-redutora, uma vez que sua presença em em baixas concentrações, aliadas a quaisquer concentrações de sulfeto, seria suficiente para a precipitação dos metais pesados (CHRISTENSEN et al., 2001). De qualquer forma, estudos de campo realizados em diversos aterros indicam que os metais pesados em águas subterrâneas impactadas por lixiviados tendem a se concentrar na porção mais próxima ao aterro em si, formando plumas de contaminação de tamanho limitado (CHRISTENSEN et al., 2001).

\section{Compostos orgânicos xenobióticos}

Compostos orgânicos xenobióticos (XOCs), que fazem parte da relação de compostos orgânicos voláteis (VOCs) e semi-voláteis (SVOCs), tem ocorrência esperada em aterros de resíduos industriais. Entretanto, a presença de XOCs em aquíferos também tem sido relacionada com diversos aterros de resíduos domiciliares. Kjeldsen e Christophersen (2001), por exemplo, detectaram a presença de XOCs em 106 aterros domiciliares na Dinamarca com mais de 15 anos.

São inúmeros os compostos orgânicos identificados em águas subterrâneas contaminadas por lixiviados. Christensen et al. (2001) e Öman e Junestedt (2008) relacionaram mais de 80 compostos que podem ser divididos nos grupos de hidrocarbonetos aromáticos voláteis, hidrocarbonetos policíclicos aromáticos, metanos, etanos e etenos clorados, fenóis, pesticidas e bifenilas policloradas (PCBs). Também são XOCs alguns produtos farmacêuticos e estrogênios potencialmente tóxicos encontrados em lixiviados (NASCIMENTOFILHO et al., 2001; BARNES et al., 2004; ZHANG et al., 2009; KAMATA et al., 2011).

A presença de XOCs em águas subterrâneas impactadas por aterros é motivo de especial preocupação em função da elevada toxidade apresentada por esses compostos, ainda que eles representem uma pequena porcentagem do carbono orgânico dissolvido na água impactada por lixiviados, em concentrações da ordem de partes por bilhão.

A atenuação das concentrações de XOCs em plumas ocorre por diluição e principalmente por sorção e degradação. Para alguns compostos, a volatilização também pode ocorrer. Segundo Christensen et al. (2001) existem poucos estudos envolvendo plumas de XOCs derivadas de aterros domiciliares. Evidências sugerem que o lixiviado, mesmo com altas concentrações de carbono orgânico dissolvido, não afeta significativamente a sorção de XOCs, de tal forma que a utilização de métodos tradicionais para a estimativa da retardação, utilizando apenas concentração da matéria orgânica do aquífero, permanecem válidas.

Em relação à degradação, os XOCs apresentam diferentes comportamentos conforme os diversos ambientes redox formados nas plumas derivadas de aterros de resíduos. Por exemplo, hidrocarbonetos aromáticos degradam rapidamente em ambientes aeróbios e compostos alifáticos clorados tem melhor degradação em ambientes redutores (FETTER, 1999). O entendimento da resposta desses compostos nas diversas zonas redox for- 
madas a partir do aterro é fundamental para a previsão dos seus comportamentos. Nesse sentido, Christensen et al. (2001) destacam que as zonas redox com maior quantidade de receptores de elétrons, como sulfato, ferro e nitrato, são as mais favoráveis para a oxidação destes compostos orgânicos. Outros autores, como Lønborg et al. (2006), calcularam taxas de decaimento de alguns XOCs (como benzeno, tolueno, xilenos, etilbenzeno e naftaleno) nas diversas zonas, encontrando as maiores nas zonas ferro-redutoras (exceto para benzeno).

\section{CONSIDERAÇÕES FINAIS}

O lixiviado de resíduos sólidos tem suas propriedades controladas por diversos fatores, tais como o clima, o relevo, os tipos de resíduos depositados, a forma de operação e o tempo de maturação do aterro. A importância desse último fator está associada à produção no aterro, ao longo do tempo, de lixiviados com diferentes composições e quantidades distintas. As principais fases representativas dessas diferentes condições podem ser de maneira simplificada classificadas em: ácida, metanogênica e de maturação, sendo a fase ácida a de maior potencial poluidor devido, principalmente, às maiores concentrações de metais pesados, DBO e DQO.

As fases que, ao longo tempo, provocam variações na composição do lixiviado no interior do aterro de resíduos sólidos também ocorrem nos aquíferos impactados por esse lixiviado. Desta maneira se espera, por exemplo, reações de acetogênese na água subterrânea impactada por lixiviados em fase ácida. Salienta-se, entretanto, que são praticamente ausentes na literatura trabalhos que abordem o impacto do lixiviado em fase ácida na água subterrânea. Por outro lado, existe significativo entendimento do impacto do lixiviado em fase metanogênica na água subterrânea. Nesta fase (que é a fase mais longa do aterro) o lixiviado cria uma sequência de zonas-redox na água subterrânea que variam de metanogênica, na proximidade do aterro, a aeróbia nas bordas da pluma. Essas zonas condicionam o comportamento das diversas substâncias dissolvidas na pluma de contaminação formada pelo lixiviado.

Estudos envolvendo a identificação de zonas-redox em águas subterrâneas impactadas por lixiviados são raros em países de clima tropical e equatorial. Assim, considerando as diferentes condições relacionadas aos tipos de substâncias ocorrentes no lixiviado e às particularidades geológicas e geoquímicas locais, é possível que sejam encontradas diferentes extensões de plumas e conformação das zonas redox em estudos de caso brasileiros em relação aos disponíveis na literatura internacional.

As substâncias que ocorrem no lixiviado e nas águas subterrâneas impactadas por resíduos sólidos podem ser agrupadas em matéria orgânica dissolvida, íons maiores, metais pesados e compostos orgânicos xenobióticos.

A matéria orgânica dissolvida sofre processos de sorção pouco significativos e a atenuação de suas concentrações está relacionada principalmente com a sua degradação, cuja meia vida em países de clima temperado situa-se em torno de 1 a 3 anos. Em regiões tropicais espera-se que esse tempo seja menor.

Os íons maiores (com exceção do conservativo cloreto) sofrem diversos processos geoquímicos, com destaque para troca iônica, redução/oxidação, complexação, precipitação e dissolução. As maiores concentrações de cloreto identificadas por Souto (2009) em lixiviados brasileiros em relação à literatura internacional pode ser indicativa de que sejam esperadas maiores plumas dessa espécie química em condições nacionais.

O grupo dos metais pesados não é considerado na literatura internacional um problema ambiental prioritário em aquíferos contaminados por lixiviados em fase metanogênica, uma vez que eles são fortemente atenuados por processos de adsorção e precipitação. Deve-se destacar, entretanto, que foram detectadas por Souto (2009), maiores concentrações de metais pesados em lixiviados em fase metanogênica em relação à principal tabela de referência internacional (Ehrig, 1983, 1988).

Embora altas concentrações de carbono orgânico dissolvido atinjam a água subterrânea em aterros de resíduos, os maiores riscos causados por aterros estão associados aos compostos orgânicos xenobióticos. O comportamento destes compostos é complexo, uma vez que existem compostos degradáveis em ambientes redutores e outros apenas em ambientes oxidantes. Para muitos compostos orgânicos, não existem informações disponíveis 
sobre a degradabilidade em ambientes fortemente redutores como os formados por lixiviados de aterros de resíduos domiciliares.

Trabalhos relacionados à recuperação de águas subterrâneas impactadas por lixiviados tem se concentrado principalmente em controle da fonte e atenuação natural monitorada. Entretanto, ainda que a atenuação natural monitorada seja um processo consensual na literatura, devido à grande complexidade geoquímica dos ambientes impactados por lixiviados, ainda permanecem questões sobre o comportamento de algumas substâncias. Assim é recomendável o uso de diversas abordagens de intervenção para recuperação ambiental dessas áreas.

\section{AGRADECIMENTOS}

À Regea Geologia e Estudos Ambientais pelo suporte financeiro ao primeiro autor e aos avaliadores anônimos cujos comentários e revisões permitiram a melhoria deste manuscrito.

\section{REFERÊNCIAS}

ABU-RUKAH, Y.; AL-KOFAHI, O. The assessment of the effect of landfill leachate on ground-water quality - a case study. El-Akader landfill site - north Jordan. Journal of Arid Environments, v. 49, n. 3, p. 615-630, 2001.

ALLISON, J.D.; BROWN, D.S.; NOVO-GRADAC, K.J. Minteqa2/Prodefa2, A Geochemical Assessment Model For Environmental Systems: Version 3.0 User's Manual; U.S. Environmental Protection Agency EPA/600/3-91/021: Athens, Georgia, 1991.

\section{APPELO, C.A.; POSTMA, D. Geochemistry, Groundwater and Pollution. A.A. Balkema:, Leiden, 2005.}

\section{ASSOCIAÇÃO BRASILEIRA DE NORMAS TÉCNICAS. NBR 15849: Resíduos sólidos urbanos - Aterros sanitários de pequeno porte - Diretrizes para localização, projeto, implanta- ção, operação e encerramento. Rio de Janeiro. 2010. 24 p}

BAEDECKER, M.J.; APGAR, M.A. Hydrogeochemical Studies at a Landfill in Delaware. In: G.S. Committee; Groundwater Contamination. p.127-138. Washington, DC: National Academic Press, 1984.

BAEDECKER, M.J.; BACK, W. Hydrogeological Process and Chemical Reactions at a Landfill. Ground water, v. 17, n. 5, p. 429-445, 1979a.

BAEDECKER, M.J.; BACK, W. Modern marine sediments as a natural analog to the chemically stressed environment of a landfill. Journal of Hydrology, v. 43, p. 393-414, 1979b.

BARBOSA, R.; OTERO, O. Caracterização da pluma de poluição originada por depósito de lixo urbano. Geochimica Brasiliensis, v. 13, n. 1, p. 51-65, 1999.

BARCELONA, M.J.; HOLM, T.R. Oxidation-reduction capacities of aquifer solids. Environmental Science \& Technology, v. 25, n. 9, p. 1565-1572, 1991.

BARNES, K.; CHRISTENSON, S.; KOLPIN, D. Pharmaceuticals and other organic waste water contaminants within a leachate plume downgradient of a municipal landfill. Ground
Water Monitoring and Remediation, v. 24, n. 2, p. 119-126, 2004.

BAUN, A.; LEDIN, A.; REITZEL, L.A.; BJERG, P.L.; Christensen, T.H. Xenobiotic organic compounds in leachates from ten Danish MSW landfills--chemical analysis and toxicity tests. Water research, v. 38, n. 18, p. 3845-58, 2004.

BAUN, A.; REITZEL, L.A.; LEDIN, A.; CHRISTENSEN, T.H.; BJERG, P.L. Natural attenuation of xenobiotic organic compounds in a landfill leachate plume (Vejen, Denmark). Journal of Contaminant Hydrology, v. 65, p. 269-291, 2003.

BAUN, D.; CHRISTENSEN, T. Speciation of Heavy Metals in Landfill Leachate: A Review. Waste Management \& Research, n. 22, p. 3-23, 2004.

BJERG, P.; RUGGE, K.; PEDERSEN, J.; CHRISTENSEN, T. Distribution of Redox-Sensitive Groundwater Quality Parameters Downgradiint of a Landdfill (Grindsted, Denmark). Environmental Science \& Technology, v. 29, n. 5, p. 1387-1394, 1995.

BJERG, P.L.; KJELDSEN, P.; CHRISTENSEN, T.H.; COZZARELLI, I. The Groundwater Geochemistry of Waste Disposal Facilities. In: H. D. Holland; K. K. Turekian; Treatise on Geochemistry. 1st ed., p.579-612. Amsterdam: Elsevier, 2003.

BOCANEGRA, E.; MASSONE, H.; MARTÍNEZ, D.; CIVIT, E.; FARENGA, M. Groundwater contamination: risk management and assessment for landfills in Mar del Plata, Argentina. Environmental Geology, v. 40, n. 6, p. 732-741, 2001.

BORTOLIN, J. R. M.; MALAGUTTI FILHO, W. Método da eletrorresistividade aplicado no monitoramento temporal da pluma de contaminação em área de disposição de resíduos sólidos urbanos. Engenharia Sanitaria e Ambiental, v. 15, n. 4, p. 367-374, 2010.

BRASIL. Conselho Nacional de Meio Ambiente. Resolução 430 de 13 de maio de 2011. Dispõe sobre as condições e padrões de lançamento de efluentes, complementa e altera a 
Resolução 357, de 17 de março de 2005. Diário Oficial da União, Brasília, DF, 16 maio 2011.

BRASIL. Lei 12.305 de 2 de agosto de 2010. Política Nacional de Resíduos Sólidos. Diário Oficial da União, Brasília, DF, 3 agosto 2010.

BRUN, A.; ENGESGAARD, P.; CHRISTENSEN, T.H.; ROSBJERG, D. Modelling of transport and biogeochemical processes in pollution plumes: Vejen landfill, Denmark. Journal of Hydrology, v. 256, n. 3-4, p. 228-247, 2002.

CHEN, P. Assessment of leachates from sanitary landfills: Impact of age, rainfall, and treatment. Environment International, v. 22, n. 2, p. 225-237, 1996.

CHRISTENSEN, T.; KJELDSEN, P.; JENSEN, D. Biogeochemistry of landill leachate plumes: review. Applied Geochemistry, v. 16, n. 7-8, p. 659-718, 2001.

CHRISTENSEN, T.H.; KJELDSEN, P. Basic biochemical process in landfills. In: Christensen, T. H., Cossu, R., Stegmann, R. Sanitary landfilling process technology and environmental impacts. Academic Press: London, 1989

CHRISTENSON, S.C.; COZZARELLI, I.M. The Norman Landfill Environmental Research Site: What Happens to the Waste in Landfills? USGS: Oklahoma, 2003.

COZZARELLI, I. M.; BÖHLKE, J. K.; MASONER, J. Biogeochemical Evolution of a Landfill Leachate Plume, Norman, Oklahoma. Ground water, v. 49, n. 5, p. 663-687, 2011.

COZZARELLI, I. M.; SUFLITA, J. M.; ULRICH, G.A. Geochemical and Microbiological Methods for Evaluating Anaerobic Processes in an Aquifer Contaminated by Landfill Leachate. Environmental Science \& Technology, v. 34, n. 18, p. 4025-4033, 2000.

CRITTO, A.; CARLON, C.; MARCOMINI, A. Characterization of contaminated soil and groundwater surrounding an illegal landfill (S. Giuliano, Venice, Italy) by principal component analysis and kriging. Environmental pollution (Barking, Essex : 1987), v. 122, n. 2, p. 235-44, 2003.

DEUTSCH, W. J. Groundwater geochemistry. Fundamentals and applications to contamination. Lewis Publishers: New York, 1997.

EHRIG, H.J. Quality and quantity of sanitary landfill leachate. Waste Management \& Research, v. 1, p. 53-68, 1983.

EHRIG, H.J. Water and elements balances of landfills: Baccini. Berlin: Springer, 1988.

ERSKINE, A. Transport of ammonium in aquifers: retardation and degradation. Quarterly Journal of Engineering Geology and Hydrogeology, v. 33, p. 161-170, 2000.

FANIN, C.A.; ROBERTS, R.D. Mature land 11 waste geochemical characteristics and implications for long-term secondary substance release. Geochemistry: Exploration, Environment, Analysis, v. 6, p. 369-377, 2006.

FERREIRA, J. A.; GIORDANO, G.; RITTER, E.; ROSSO, T. C. A.; CAMPOS, J. C.; LIMA, P. Z. M. Uma revisão das técnicas de tratamento de chorume e a realidade do Estado do Rio de Janeiro. In: Congresso Brasileiro de Engenharia Sanitá- ria e Ambiental, 21, 2001, João Pessoa. Anais... Rio de Janeiro: ABES, 2001, p.26-34.

FETTER, C.W. Contaminant Hydrogeology. 2nd ed. Prentice Hall: New Jersey. 1999.

FREITAS, J.G.; FLETCHER, B.; ARAVENA, R.; BARKER, J.F. Methane production and isotopic fingerprinting in ethanol fuel contaminated sites. Ground water, v. 48, n. 6, p. 844-57, 2010.

GIORDANO, G. Chorume - técnicas de tratamento e monitoramento. In: Seminário Internacional "As melhores práticas em gestão integrada de resíduos sólidos”, 2003, Rio de Janeiro, RJ. Anais... Rio de Janeiro: Secretaria de Estado do Meio Ambiente e Desenvolvimento Urbano, Governo do Estado do Rio de Janeiro; Banco Interamericano de Desenvolvimento (BID). p. 210-218.

HERON, G.; BJERG, P.; GRAVESEN, P.; LUDVIGSEN, L.; CHRISTENSEN, T. Geology and sediment geochemistry of a landfill leachate contaminated aquifer (Grindsted, Denmark). Journal of Contaminant Hydrology, v. 29, p. 301-317, 1998.

HERON, G.; CHRISTENSEN, T. H. Impact of SedimentBound Iron on Redox Buffering in a Landfill Leachate Polluted Aquifer (Vejen, Denmark). Environmental Science \& Technology, v. 29, p. 187-192. doi: 10.1021/es00001a024, 1995.

HERON, G.; CHRISTENSEN, T.H. Impact of SedimentBound Iron on Redox Buffering in a Landfill Leachate Polluted Aquifer (Vejen, Denmark). Environmental Science \& Technology, v. 29, p. 187-192, 1995.

HYPOLITO, R.; EZAKI, S. Íons de metais pesados em sistema solo-lixo-chorume-água de aterros sanitários da região metropolitana de são paulo-sp. Águas Subterrâneas, v. 20, n. 1, p. 99-114, 2006.

INSTITUTO BRASILEIRO DE GEOGRAFIA E ESTATÍSTICA. Pesquisa nacional de saneamento básico de 2008 . 1.ed., IBGE: Rio de Janeiro, 2010.

INTERSTATE TECHNOLOGY REGULATORY COUNCIL. Characterization, Design, construction, and monitoring of bioreactor landfills; ITRC: Washington DC, 2006.

JAGER, E., XANDER, L., RUBEN, H. Medical waste. 1. Microbiologic studies of various specialists at a large and small hospital in comparison to housekeeping waste. Zentralblatt fur Hygiene und Umweltmedizin. v. 188, 343-364. 1989.

JENSEN, D.L.; CHRISTENSEN, T.H. Colloidal and dissolved metals in leachates from four Danish landfills. Water Research, v. 33, n. 9, p. 2139-2147, 1999.

JORSTAD, L.B.; JANKOWSKI, J.; ACWORTH, R.I. Analysis of the distribution of inorganic constituents in a landfill leachate-contaminated aquifer Astrolabe Park, Sydney, Australia. Environmental Geology, v. 16, p. 263-272, 2004.

KAMATA, R.; SHIRAISHI, F.; NAKAJIMA, D.; KAGEYAMA, S. Estrogenic effects of leachates from industrial waste landfills measured by a recombinant yeast assay and transcriptional analysis in Japanese medaka. Aquatic toxicology (Amsterdam), v. 101, n. 2, p. 430-7, 2011. 
KEHEW, A.E. Applied chemical hydrogeology, 1st ed., Prentice-Hall: Upper Saddle River, 2001.

KJELDSEN, P.; BARLAZ, M. A.; ROOKER, A. P. Present and Long-Term Composition of MSW Landfill Leachate: A Review. Critical Reviews in Environmental Science and Technology, v. 32, n. 4, p. 297-336, 2002.

KJELDSEN, P.; CHRISTENSEN, T. Soil attenuation of acid phase landfill leachate. Waste Management \& Research, v. 2, p. 247-263, 1984.

KJELDSEN, P.; CHRISTOPHERSEN, M. Composition of leachate from old landfills in Denmark. Waste Management \& Research, n. 19, p. 249-256, 2001.

KLINCK, B. A.; STUART, M.E. Human health risk in relation to landfill leachate quality; Overseas G. ed.; British Geological Survey: Keyworth, UK, 1999.

LAGO, A. L.; ELIS, V. R.; GIACHETI, H. L. Aplicação integrada de métodos geofísicos em uma área de disposicao de resíduos sólidos urbanos em Bauru-SP. Revista Brasileira de Geofísica, v. 24, n. 3, p. 357-374, 2006.;

LEE, J.; CHEON, J.; KWON, H. Attenuation of landfill leachate at two uncontrolled landfills. Environmental Geology, v. 51, n. 4, p. 581-593, 2006.

LI, R.; YUE, D.; LIU, J.; NIE, Y. Size fractionation of organic matter and heavy metals in raw and treated leachate. Waste Management, v. 29, n. 9, p. 2527-33, 2009.

LOIZIDOU, M.; KAPETANIOS, E. Effect of leachate from landfills on underground water quality. The Science of The Total Environment, v. 128, n. 1, p. 69-81, 1993.

LØNBORG, M. J.; ENGESGAARD, P.; BJERG, P. L.; ROS BJERG, D. A steady state redox zone approach for modeling the transport and degradation of xenobiotic organic compounds from a landfill site. Journal of contaminant hydrology, v. 87, n. 3-4, p. 191-210, 2006.

LOPES, A. A.; BRIGANTE, J.; SCHALCH, V. Influência do Aterro Sanitário de São Carlos (SP), Brasil, na Qualidade das Águas Superficial e Subterrânea. J. Braz. Soc. Ecotoxicol., v. 2, n. 2, p. 115-127, 2007.

MOURA, C. L. D. Íons metálicos (Al, Fe, Mn e Pb) associados a aterros (sanitário e industrial) no município de Tremembé/SP, 2008. 122 p. Tese (Doutorado em geociências) Instituto de Geociências, Universidade de São Paulo, 2008.

LOPES, M.G.A.; CONDE, M.C. O aterro sanitário como bioreactor: desafios geotécnicos. Geotecnia. v. 114, p. 47-70, 2008 .

LORAH, M.M.; COZZARELLI, I.M.; BÖHLKE, J.K. Biogeochemistry at a wetland sediment-alluvial aquifer interface in a landfill leachate plume. Journal of contaminant hydrology, v. 105, n. 3-4, p. 99-117, 2009.

LUDVIGSEN, L.; ALBRECHTSEN, H.; RINGELBERG, D.; EKELUND, F.; CHRISTENSEN, T. Distribution and Composition of Microbial Populations in a Landfill Leachate Con- taminated Aquifer (Grindsted, Denmark). Microbial Ecology, v. 37, n. 3, p. 197-207, 1999.

LYNGKILDE, J.; CHRISTENSEN, T.H. Fate of organic contaminants in the redox zones of a landfill leachate pollution plume (Vejen, Denmark). Journal of Contaminant Hydrology, v. 10 , n. 4, p. 291-307, 1992 b.

LYNGKILDE, J.; CHRISTENSEN, T.H. Redox zones of a landfill leachate pollution plume (Vejen, Denmark). Journal of Contaminant Hydrology, v. 10, p. 273-289, 1992a.

MACFARLANE, D.S.; CHERRY, J.A.; GILLHAM, R.W.; SUDICKY, E.A. Migration of contaminants in groundwater at a landfill: a case study. 1 Groundwater Flow and Plume Delineation. Journal of Hydrology, v. 63, p. 1-29, 1983.

MARTINEZ, D.; MASSONE, H.; CERÓN GARCIA, J.; FARENGA, M.; FERRANTE, A. Hidrogeoquimica del area de disposicion final de residuos de Mar del Plata, Argentina. Boletín Geológico y Minero, n. 114, p. 237-246, 2003.

MCBEAN, E.A.; ROVERS, F.A.; FARQUHAR, G.J. Solid waste landfill engineering and design. Prentice-Hall: Englewood Cliffs, 1995.

MONDELLI, G.; GIACHETI, H. L.; BOSCOV, M. E. G.; ELIS, V. R.; HAMADA, J. Geoenvironmental site investigation using different techniques in a municipal solid waste disposal site in Brazil. Environmental Geology, v. 52, n. 5, p. 871-887, 2006.

MURRAY, J.; ROUSE, J.V.; CARPENTER, A.B. Groundwater contamination by sanitary landfill leachate and domestic wastewater in carbonate terrain: Principal source diagnosis, chemical transport characteristics and design implications. Water Research, v. 15, n. 6, p. 745-757, 1981.

NASCIMENTO-FILHO, I.D.; MÜHLEN, C.V.; CARAMÃO, E.B. Estudo de compostos orgânicos em lixiviado de aterros sanitários por EFS e CG/EM. Quim. Nova, v. 24, n. 4, p. 554$556,2001$.

NICHOLSON, R.; CHERRY, J.; REARDON, E. Migration of contaminants in groundwater at a landfill: A case study 6 . Hydrogeochemistry. Journal of Hydrology, v. 63, n. 1-2, p. 131-176, 1983.

ÖMAN, C.B.; JUNESTEDT, C. Chemical characterization of landfill leachates. 400 parameters and compounds. Waste management (New York, N.Y.), v. 28, n. 10, p. 1876-91, 2008.

PARISOT, E.H.; GUIGUER, N.; REBOUÇAS, A.C.; CABRAL, D.; DUARTE, U. Monitoramento das águas subterrâneas adjacentes ao aterro sanitário de Taubaté (SP) - primeiros resultados. Boletim IG-USP: Série Científica, v. 16, p. 3245, 1985.

PARKHURST, B.D.; APPELO, C.A. User's Guide To Phreeqc (Version 2) - A Computer Program for Speciation And Inverse Geochemical Calculations; U.S. Geological Survey: Denver, Colorado, 1999.

PEEL, M.C.; FINLAYSON, B.L.; MCMAHON, T.A. Updated world map of the Köppen-Geiger climate classification. 
Hydrology and Earth System Sciences Discussions, v. 4, n 2, p. 439-473, 2007.

POHLAND, F.; HARPER, S. Critical review and summary of leachate and gas production from landfills; EPA/600/286/073: Washington DC, 1985.

RAPTICAPUTO, D.; VACCARO, C. Geochemical evidences of landfill leachate in groundwater. Engineering Geology, v 85 , n. 1-2, p. 111-121, 2006

ROLING, W.F.; VAN-BREUKELEN, B.M.; BRASTER, M.; LIN, B.; VAN-VERSEVELD, H.W. Relationships between Microbial Community Structure and Hydrochemistry in a Landfill Leachate-Polluted Aquifer. Applied and Environmental Microbiology, v. 67, n. 10, p. 4619-4629, 2001.

ROSE, S.; LONG, A. Monitoring Dissolved Oxygen in Ground Water: Some Basic Considerations. Ground Water Monitoring \& Remediation, p. 93-97, 1988.

SCHWARZENBACH, R.; WESTALL, J. Transport of Nonpolar Organic Compounds from Surface Water to Groundwater. Laboratory Sorption Studies. Environmental Science \& Technology, n. 8, p. 1360-1367, 1981.

SINGH, U.K.; KUMAR, M.; CHAUHAN, R.; JHA, P.K. Assessment of the impact of landfill on groundwater quality: A case study of the Pirana site in western India. Environmental Monitoring and Assessment, v. 141, p. 309-321, 2008

SOUTO, G. Lixiviado de aterros sanitários brasileiros estudo de remoção do nitrogênio amoniacal por processo de arraste com ar ("stripping"). 371 p. Tese Doutorado EESC, Universidade de São Paulo, São Carlos, 2009.
UNIVERSIDADE FEDERAL DO PARANÁ. Chorume. Última atualização 27 mar. 2009. Disponível em <http://www.quimica.ufpr.br/tecnotrater/chorume.htm>. Acesso em 15 mai. 2012

VAN BREUKELEN, B.M. Natural Attenuation of Landfill Leachate: a Combined Biogeochemical Process Analysis and Microbial Ecology Approach. 2003. 154 f. PhD Thesis - Faculty of Earth and Life Sciences, Vrije Universiteit Amsterdam, Amsterdam, 2003.

VAN BREUKELEN, B.M.; ROLING, W.; GROEN, J.; GRIFFIOEN, J.; VERSEVELD, H.W. Biogeochemistry and isotope geochemistry of a landfill leachate plume. Journal of Contaminant Hydrology, v. 65, p. 245 - 268, 2003.

WEISS, J.V.; COZZARELLI, I.M. Biodegradation in contaminated aquifers: incorporating microbial/molecular methods. Ground water, v. 46, n. 2, p. 305-22, 2008.

ZHANG, H.; CHANG, C.; LÜ, F. Estrogenic activity of fractionate landfill leachate. The Science of the total environment, v. 407, n. 2, p. 879-86, 2009.

ZUME, J.T.; TARHULE, A.; CHRISTENSON, S. Subsurface Imaging of an Abandoned Solid Waste Landfill Site in Norman , Oklahoma. Ground Water Monitoring \& Remediation, v. 26, n. 2, p. 62-69, 2006. 